\title{
MODELLING THE SECTORAL STRUCTURE OF THE FINAL OUTPUT ${ }^{1}$
}

\begin{abstract}
Emilian DOBRESCU ${ }^{2}$
Abstract

This paper examines the modelling complications that appear when some macroeconomic behavioral relationships interact with structural variables, even under a given A matrix. The main problem is related to the situation when: a) the final consumption, gross fixed capital formation, inventory changes, export, import (all of them at market prices), and gross value added (at production prices) are estimated as macro-indicators; and b) the output (at production prices) is determined at a disaggregated level. The so-called demand-side or supply-side approaches are possible; here, the supply-side approach is in focus.

With such a goal, the regression and linear weighted average (in the Fisher version) techniques are discussed as the main tools for estimating sectoral weights of the final output. For the linear weighted average method, the paper sketches - as a discussion proposal - a methodology for the optimal selection of the length (number of terms) of the moving average. As a primary database, the Romanian input-output tables for 1989-2009, aggregated into 10 sectors, were used.
\end{abstract}

Keywords: final output, sectoral structure, regression, moving average JEL Classification: C32, C36, C43, C67

\section{The Problem}

1. The models combining the main behavioral macroeconomic relationships (of Keynesian or post-Keynesian types) with variables related to the structural profile of the economy (as in Dobrescu, 2006, for instance) have to solve a challenging problem. Technically, the difficulty of such an attempt results from the fact that some indicators are defined at the global level, while others at the sectoral one. We discuss this question under the following assumptions:

- The final consumption, gross fixed capital formation, inventory changes, export, import (all at market prices), and gross value added (at production prices) are estimated as macro-indicators.

\footnotetext{
1 This study was presented at 2013 Global Business, Economics, and Finance Conference, Wuhan University, China, 9-11 May 2013.

2 Centre for Macroeconomic Modelling, National Institute of Economic Research. Romanian Academy. E-mail: emiliand@clicknet.ro.
} 
- The output (evidently, at production prices) is determined on a sectoral basis, according to the adopted branch classification; an aggregate indicator in this case also can be computed, but only by summing up sectoral data.

In such an analysis, the input-output (I-O) tables are irreplaceable searching tools (the main coordinates can be found, for instance, in Leontief, 1970; 1986; Stone, 1961; United Nations, 1999; Miller and Blair, 2009). More concretely, if the A matrix is given, a consistent interaction between the mentioned levels could be obtained in different ways. Two such methods already were implemented in the Romanian modelling activity. The first, termed as the demand-side approach, consists in essence of an econometric estimation of utilization of resources. Symmetrically, the other one focuses on final outputs and it is termed as the supply-side approach.

2. For example, the demand-side approach was applied to the 2005 version of the Romanian macromodel (Dobrescu, 2006). The leading relationships involved in such a case are described below.

$$
C_{i j}=Q_{i} * a_{i j}
$$

Cij - intermediate consumption from sector $\mathrm{i}$ in sector $\mathrm{j}$, current prices

Qi - output in sector i, current prices

aij - technical coefficients, current prices - exogenous

$$
G V A=G D P-N I T
$$

GVA - total gross value added, current prices

GDP - gross domestic product, current prices; defined by macroeconomic relationships

NIT - total net indirect taxes; defined by macroeconomic relationships

$$
U F=G D P+M
$$

UF - total final resources, current prices

M - import of goods and services, current prices; defined by macroeconomic relationships

$$
G V A=\sum G V A_{i}
$$

$\mathrm{GVA}_{\mathrm{i}}$ - gross value added in sector i, current prices

$$
\begin{aligned}
& \left.G V A_{i}=Q_{i} *\left(1-\sum a_{i j}\right)\right) \text { for i fixed } \\
& Q_{i}=D R_{i}-\left(w m_{i} * M+N I T^{*} w n_{i}\right)
\end{aligned}
$$

$\mathrm{DR}_{\mathrm{i}}$ - total resources of sector $\mathrm{i}$, current prices

$w_{i}$ - weight of sector $\mathrm{i}$ in import; econometric estimation

$\mathrm{wn}_{\mathrm{i}}$ - weight of sector $\mathrm{i}$ in total of net indirect taxes, econometric estimation

$$
D R_{i}=U F_{i}+\sum a_{i j} * Q_{j} \text { for i fixed }
$$

$U F_{i}$ - final resources of sector $i$, current prices 
Modelling the Sectoral Structure of the Final Output

$$
U F_{i}=c w_{i} * F C+f w_{i} * G F C F+x w_{i} * X+s w_{i} * S T O C K \quad \mathrm{i}=1,2 \ldots 10
$$

$\mathrm{CW}_{\mathrm{i}}$ - weight of sector $\mathrm{i}$ in final consumption; econometric estimation

FC - total final consumption, current prices; defined by macroeconomic relationships

$\mathrm{fw}_{\mathrm{i}}$ - weight of sector $\mathrm{i}$ in gross capital formation; econometric estimation

GFCF - total gross capital formation, current prices; defined by macroeconomic relationships

$\mathrm{xw}_{\mathrm{i}}$ - weight of sector $\mathrm{i}$ in export of goods and services

$X$ - total export of goods and services, current prices; defined by macroeconomic relationships

$\mathrm{SW}_{\mathrm{i}}$ - weight of sector $\mathrm{i}$ in change of inventories; econometric estimation

STOCK - total change in inventories, current prices; defined by macroeconomic relationships.

The demand-side approach involves, therefore, a very difficult operation of consistently determining six sectoral distributions, $\mathrm{wm}_{\mathrm{i}}, \mathrm{wn}_{\mathrm{i}}, \mathrm{cw}_{\mathrm{i}}, \mathrm{fw}_{\mathrm{i}}, \mathrm{wx}_{\mathrm{i}}$, and $\mathrm{ws}_{\mathrm{i}}$, under the restriction $\Sigma w_{i}=\Sigma w n_{i}=\Sigma c w_{i}=\Sigma f w_{i}=\Sigma w x_{i}=\Sigma w s_{i}=1$.

3. The supply-side approach was applied to the integrated system of the 2012 version of the Romanian macromodel (National Commission for Prognosis, 2013). This is centered on the final output $\left(\mathrm{NY}_{\mathrm{i}}\right)$ as a difference between output (production) of each sector and its total deliveries for intermediate consumption in the whole economy (namely $Q_{i}-\sum a_{i j} Q_{j}$, i=fixed, at the sectoral level, and $N Y=\Sigma N Y_{i}$, at the aggregate level). According to NY, the newly created resources of the economy are determined at basic prices (as the output itself), and under the restriction of null foreign trade balance. Several algebraic transformations drive us to an important accounting equality. Therefore,

$$
\begin{aligned}
N Y_{i}=F C_{i}+G F C F_{i} & S_{T O C K_{i}+X_{i}-M_{i}-N I T_{i}} \\
N Y=\sum F C_{i}+\sum G F C F_{i}+\sum & S T O C K_{i}+\sum X_{i}-\sum M_{i}-\sum N I T_{i} \\
F C & =\sum_{i} F C_{i} \\
G F C F & =\sum_{i} G F C F_{i} \\
S T O C K & =\sum_{i} S_{i} T O K_{i} \\
X & =\sum_{i} X_{i} \\
M & =\sum_{i} M_{i} \\
N I T & =\sum_{i} N I T_{i} \\
N Y=F C+G F C F & +S T O C K+X-M=N I T \\
G D P=F C+G F C F+S T O C K+X-M &
\end{aligned}
$$


Finally,

$$
N Y=G D P-N I T=G V A
$$

As already mentioned, in our set of adopted assumptions, the total gross value added results (as in the previous approach) from the macroeconomic relationships. Note, however, that the equality $N Y=G V A$ is valid only at the macroeconomic level. At the sectoral level significant differences are possible, depending on the external and internal competitiveness of different branches. If the sectoral distribution wny $y_{i}$ $\left(w_{n} y_{i}=N Y_{i} / N Y\right)$ is approximated, then the following inferences are evident:

$$
\begin{gathered}
Q_{i}=\sum a_{i j} Q_{j}+N Y_{i}=\sum a_{i j} Q_{j}+w n y_{i} * N Y \quad \mathrm{i}=\mathrm{fixed} \\
Q_{j}=\sum a_{i j} Q_{j}+G V A_{j} \quad \mathrm{j}=\mathrm{fixed} \\
G V A_{j}=Q_{j}-\sum a_{i j} Q_{j}=Q_{j} *\left(1-\sum a_{i j}\right)=Q_{j} *\left(1-s c a_{j}\right) \quad \mathrm{j}=\mathrm{fixed}
\end{gathered}
$$

where: sca $a_{j}$ represent the colSums of technical coefficients $a_{i j}$. Consequently,

$$
G V A_{i}=\left(1-s c a_{i}\right) *\left(\sum a_{i j} \frac{G V A_{j}}{1-s c a_{j}}+w n y_{i} * N Y\right) \quad \mathrm{i}=\mathrm{fixed}
$$

Then, it is simple to determine the global output of sectors. The supply-side approach needs, therefore, to estimate (econometrically or otherwise) only the distribution wny . $_{\text {. }}$ We must outline that this entire discussion relates to the sectoral structure of output (production and gross value added) and not to other sectoral indicators. For such a limited purpose, the supply-side approach is simpler and reduces the necessary sectoral distribution vectors from six (as in the demand-side approach) to only one.

4. The purpose of our paper is to illustrate the supply-side approach using Romanian input-output tables (annual data for the period 1989-2009). The extended classification, comprising 105 branches (NIS, 2012), was aggregated into 10 sectors (Dobrescu, 2009; National Commission for Prognosis, 2012), according to the following encoding:

- Agriculture, forestry, hunting and fishing (suffix 1)

- Mining and quarrying (suffix 2)

- Production and distribution of electric and thermal power (suffix 3)

- Food, beverages and tobacco (suffix 4)

- Textiles, leather, pulp and paper and furniture (suffix 5)

- Machinery and equipment, transport means and other metal products (suffix 6)

- Other manufacturing industries (suffix 7)

- Constructions (suffix 8)

- Transports and post and telecommunications (suffix 9)

- Trade, business and public services (suffix 10)

The first three positions belong to the primary mega-sector. The following ones constitute the manufacturing industry, which - together with constructions - configure 


\section{Modelling the Sectoral Structure of the Final Output}

the secondary mega-sector. The last two positions can be considered as the tertiary mega-sector. The series wny $y_{i}$ is detailed in Annex 1.

5. The rest of the paper is organized as follows: the possibilities to estimate the set of $w y_{i}$ by using, on the one hand, econometric regressions and, on the other hand, a weighted linear moving average are discussed in sections II and III. Their specific advantages and limits are outlined. The final part of this paper presents several concluding remarks.

\section{Econometric Regressions}

1. The series wny $y_{i}$ was submitted to two tests of stationarity: Augmented Dickey-Fuller (ADF) and Phillips-Perron (PP) in three variants concerning exogenous variables (none, constant and constant and linear trend) and three forms of series (primary data and first-order and second-order differences). The results are detailed in Annex 2. Although some series are I(0), in the proposed specification the first-order differences are used as dependent variables in all the ten equations.

2. Concerning the right side of the regressions, different solutions are possible. In order to avoid irrelevance and complications for our analysis, the paper does not involve other variables besides the statistical series of wny $\mathrm{y}_{\mathrm{i}}$ themselves.

A careful examination of the data shows, however, that it would be risky to use only the simple autoregressions (that is, exclusively, lags and differences of every estimated variable). Table 1 presents the Galtung-Pearson correlations (in module) recorded during 1990-2009 between all the wny . $_{\text {. }}$

Table 1

Galtung-Pearson Correlations

\begin{tabular}{|c|c|c|c|c|c|c|c|c|c|c|}
\hline Module & wny9 & wny4 & wny10 & wny6 & wny5 & wny7 & wny1 & wny3 & wny2 & wny8 \\
\hline wny9 & 1 & 0.8128 & 0.8422 & 0.9044 & 0.8972 & 0.6993 & 0.3771 & 0.6471 & 0.6596 & 0.038 \\
\hline wny4 & 0.8128 & 1 & 0.847 & 0.6246 & 0.7033 & 0.808 & 0.6167 & 0.4632 & 0.5524 & 0.4459 \\
\hline wny10 & 0.8422 & 0.847 & 1 & 0.7993 & 0.7509 & 0.9068 & 0.6226 & 0.5157 & 0.5068 & 0.1508 \\
\hline wny6 & 0.9044 & 0.6246 & \begin{tabular}{|l}
0.7993 \\
\end{tabular} & 1 & 0.9471 & 0.5643 & 0.1522 & 0.6281 & 0.7181 & 0.2427 \\
\hline wny5 & 0.8972 & 0.7033 & 0.7509 & 0.9471 & 1 & 0.5238 & 0.1286 & 0.6217 & 0.7345 & 0.0891 \\
\hline wny7 & 0.6993 & 0.808 & 0.9068 & 0.5643 & 0.5238 & 1 & 0.6592 & 0.3948 & 0.2471 & 0.3068 \\
\hline \begin{tabular}{|l|} 
wny1 \\
\end{tabular} & 0.3771 & 0.6167 & 0.6226 & 0.1522 & 0.1286 & 0.6592 & 1 & 0.218 & 0.0759 & 0.7079 \\
\hline wny3 & 0.6471 & 0.4632 & 0.5157 & 0.6281 & 0.6217 & 0.3948 & 0.218 & 1 & 0.2256 & 0.016 \\
\hline wny2 & 0.6596 & 0.5524 & 0.5068 & 0.7181 & 0.7345 & 0.2471 & 0.0759 & 0.2256 & 1 & 0.1383 \\
\hline wny8 & 0.038 & 0.4459 & 0.1508 & 0.2427 & 0.0891 & 0.3068 & 0.7079 & 0.016 & 0.1383 & 1 \\
\hline Legend & $0.8-1$ & & & & & & & & & \\
\hline & $0.6-0.8$ & & & & & & & & & \\
\hline & $0.4-0.6$ & & & & & & & & & \\
\hline & $0.2-0.4$ & & & & & & & & & \\
\hline & $<0.2$ & & & & & & & & & \\
\hline
\end{tabular}

Therefore, out of 45 bilateral coefficients, 8 exceed $80 \%$ and 15 are situated between $60-80 \%$; the group between $40-60 \%$ includes 7 positions as well. In other words, the 
registered co-movements in the evolution of different sectoral weights of the final output cannot be ignored.

3. The final retained specification contains 35 estimators. In many cases lags and differences of other wny than those estimated are involved. More formally, the solved system shows as follows (SySw):

$$
\begin{gathered}
d(w n y 1)=c(1)+c(2) * w n y 1(-1)+c(3) * \frac{t}{t+1} \\
d(w n y 2)=c(4)+c(5) * w n y 2(-1)+c(6) * w n y 6(-1) \\
d(w n y 3)=c(7)+c(8) * w n y 3(-1)+c(6) * w n y 6(-1) \\
d(w n y 4)=c(10)+c(11) * w n y 4(-1)+c(12) * w n y 1(-1)+c(13) * w n y 2(-1) \\
d(w n y 5)=c(14)+c(15) * w n y 5(-1) \\
d(w n y 6)=c(16)+c(17) * w n y 6(-1)+c(18) * d(w n y 10) \\
d(w n y 7)=c(19)+c(20) * w n y 7(-1)+c(21) * w n y 4+c(22) * d(w n y 6,2) \\
+c(23) * d(w n y 10(-1)) \\
d(w n y 8)=c(24)+c(25) * w n y 8(-1)+c(26) * w n y 4(-1) \\
d(w n y 9)=c(27)+c(28) * w n y 9(-1)+c(29) * w n y 2(-1) \\
d(w n y 10)=c(30)+c(31) * w n y 10(-1)+c(32) * d(w n y 2,2)+c(33) * d(w n y 6) \\
+c(34) * d(w n y 6,2)+c(35) * d(w n y 9(-1))
\end{gathered}
$$

According to the symbolism of EViews, $d\left(w_{n} y_{i}\right)$ represents the first-order difference and $d\left(w_{n} y_{i}, 2\right)$ the second-order difference.

4. The system SySw was solved by six techniques (Annex 3): ordinary least squares (OLS), weighted least squares (WLS), seemingly unrelated regression (SUR), twostage least squares (2SLS), weighted two-stage least squares (W2LS), and threestage least squares (3SLS). Two circumstances concerning the obtained estimators are important:

a) in all cases the null hypothesis is significantly rejected; and

b) the algebraic signs of all the estimators are independent of the applied technique.

Under these conditions, the R-squared coefficient was used as a discriminating criterion (Table 2)

GraphR1 shows the comparative levels of the adjusted R-squared coefficients for the first five equations (d(wny1)-d(wny5). 
Table 2

\section{Coefficients of Determination}

\begin{tabular}{|l|l|l|l|l|l|l|l|}
\hline Equation & & \multicolumn{1}{|c|}{ OLS } & \multicolumn{1}{|c|}{ WLS } & \multicolumn{1}{c|}{ SUR } & \multicolumn{1}{|c|}{ 2SLS } & W2SLS & \multicolumn{1}{c|}{ 3SLS } \\
\hline $\mathrm{d}$ (wny1) & R-squared & 0.754063 & 0.754063 & 0.751292 & 0.731128 & 0.731128 & 0.731128 \\
\hline & Adjusted R-squared & 0.72513 & 0.72513 & 0.722032 & 0.699496 & 0.699496 & 0.699496 \\
\hline $\mathrm{d}$ (wny2) & R-squared & 0.428807 & 0.428807 & 0.424202 & 0.377581 & 0.377581 & 0.377581 \\
\hline & Adjusted R-squared & 0.361608 & 0.361608 & 0.356461 & 0.304355 & 0.304355 & 0.304355 \\
\hline $\mathrm{d}$ (wny3) & R-squared & 0.591066 & 0.591066 & 0.588717 & 0.548066 & 0.548066 & 0.548066 \\
\hline & Adjusted R-squared & 0.542956 & 0.542956 & 0.540331 & 0.491574 & 0.491574 & 0.491574 \\
\hline $\mathrm{d}$ (wny4) & R-squared & 0.659118 & 0.659118 & 0.640439 & 0.61548 & 0.61548 & 0.61548 \\
\hline & Adjusted R-squared & 0.595203 & 0.595203 & 0.573021 & 0.538576 & 0.538576 & 0.538576 \\
\hline $\mathrm{d}$ (wny5) & R-squared & 0.683628 & 0.683628 & 0.68317 & 0.527534 & 0.527534 & 0.527534 \\
\hline & Adjusted R-squared & 0.666052 & 0.666052 & 0.665569 & 0.499742 & 0.499742 & 0.499742 \\
\hline $\mathrm{d}$ (wny6) & R-squared & 0.813574 & 0.813574 & 0.809646 & 0.782508 & 0.782508 & 0.782508 \\
\hline & Adjusted R-squared & 0.791641 & 0.791641 & 0.787252 & 0.755321 & 0.755321 & 0.755321 \\
\hline $\mathrm{d}$ (wny7) & R-squared & 0.686302 & 0.686302 & 0.68297 & 0.6795 & 0.6795 & 0.6795 \\
\hline & Adjusted R-squared & 0.596674 & 0.596674 & 0.592389 & 0.587929 & 0.587929 & 0.587929 \\
\hline $\mathrm{d}$ (wny8) & R-squared & 0.451842 & 0.451842 & 0.450727 & 0.305167 & 0.305167 & 0.305167 \\
\hline & Adjusted R-squared & 0.387352 & 0.387352 & 0.386107 & 0.223422 & 0.223422 & 0.223422 \\
\hline $\mathrm{d}$ (wny9) & R-squared & 0.577444 & 0.577444 & 0.570186 & 0.521291 & 0.521291 & 0.521291 \\
\hline & Adjusted R-squared & 0.527732 & 0.527732 & 0.51962 & 0.461452 & 0.461452 & 0.461452 \\
\hline $\mathrm{d}$ (wny10) & R-squared & 0.881757 & 0.881757 & 0.862468 & 0.873684 & 0.873684 & 0.873684 \\
\hline & Adjusted R-squared & 0.83628 & 0.83628 & 0.809572 & 0.825101 & 0.825101 & 0.825101 \\
\hline
\end{tabular}

\section{GraphR1}

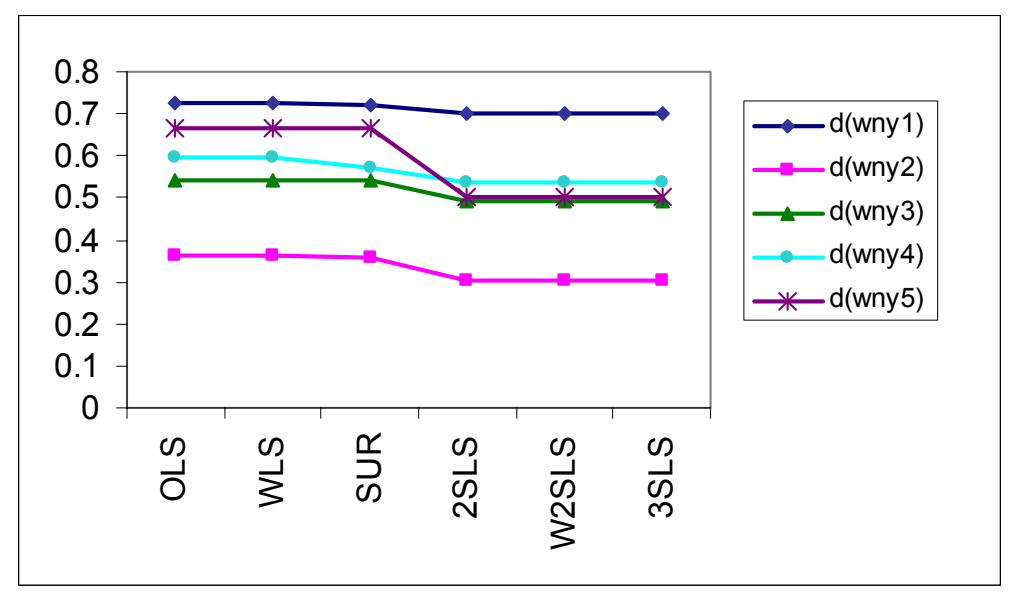

Generally, the coefficients of determination are equal in the case of OLS and WLS and higher than those provided by other procedures.

The situation is identical for the second half of equations (d(wny6)- $d($ wny10)) represented in GraphR2. 


\section{GraphR2}

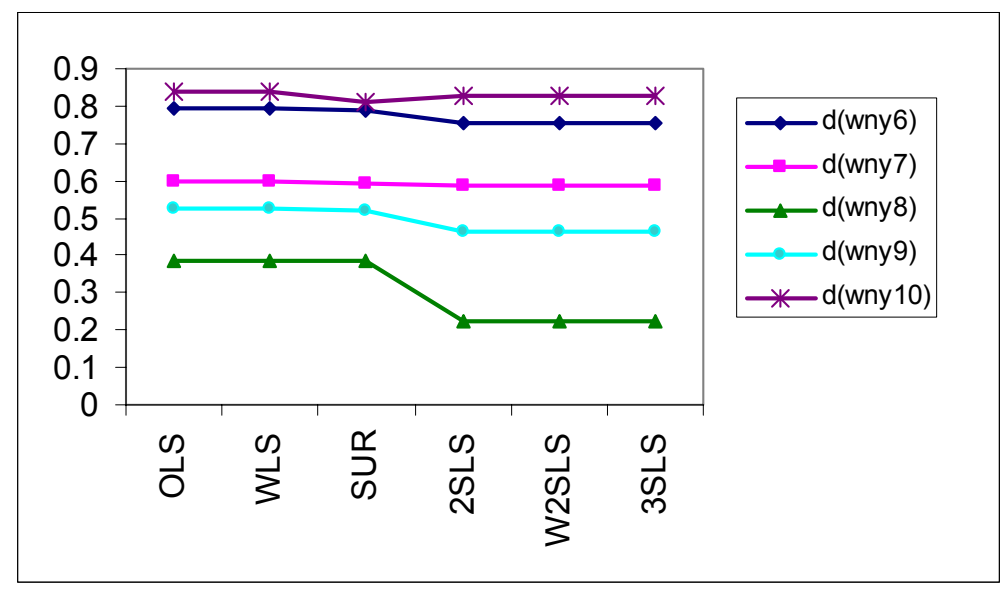

Consequently, our application uses the OLS econometric results.

5. Moreover, the coefficient, residual, and stability diagnostics do not invalidate them.

5.1. The variance inflation-factor test is presented in Table 3.

Table 3

Variance Inflation Factors (VIF)

\begin{tabular}{|c|c|c|c|c|c|c|c|}
\hline Equation & Variable & $\begin{array}{c}\text { Coefficient } \\
\text { variance }\end{array}$ & $\begin{array}{c}\text { Centered } \\
\text { VIF }\end{array}$ & Equation & Variable & $\begin{array}{c}\text { Coefficient } \\
\text { variance }\end{array}$ & $\begin{array}{c}\text { Centered } \\
\text { VIF }\end{array}$ \\
\hline \multirow[t]{3}{*}{$d($ wny1) } & C & 0.002482 & $\mathrm{Na}$ & $d($ wny 7$)$ & C & 0.000256 & na \\
\hline & wny1(-1) & 0.00855 & 1.041996 & & wny7(-1) & 0.016891 & 2.247643 \\
\hline & $t /(t+1)$ & 0.002674 & 1.041996 & & wny4 & 0.017399 & 2.187514 \\
\hline \multirow[t]{3}{*}{ d(wny2) } & C & 2.42E-05 & na & & $d($ wny6,2) & 0.028301 & 1.36685 \\
\hline & wny2(-1) & 0.023048 & 1.217922 & & d(wny10(-1)) & 0.004816 & 1.297817 \\
\hline & d(wny6(-1)) & 0.010297 & 1.217922 & d(wny8) & $\mathrm{C}$ & 0.000612 & na \\
\hline \multirow[t]{3}{*}{$d(w n y 3)$} & $\mathrm{C}$ & $5.16 \mathrm{E}-05$ & na & & wny8(-1) & 0.017393 & 1.156796 \\
\hline & wny3(-1) & 0.053487 & 1.649276 & & wny4(-1) & 0.014873 & 1.156796 \\
\hline & wny6(-1) & 0.002156 & 1.649276 & d(wny9) & $\mathrm{C}$ & 0.000121 & na \\
\hline \multirow[t]{4}{*}{$d$ (wny4) } & $\mathrm{C}$ & 3.77E-05 & na & & Wny9(-1) & 0.003289 & 1.789711 \\
\hline & wny4(-1) & 0.005824 & 2.590451 & & Wny2(-1) & 0.034893 & 1.789711 \\
\hline & wny1(-1) & 0.001921 & 1.742686 & $\mathrm{~d}($ wny 10) & $\mathrm{C}$ & 0.001541 & na \\
\hline & wny2(-1) & 0.032865 & 1.746076 & & wny10(-1) & 0.005785 & 2.672029 \\
\hline \multirow[t]{2}{*}{$d(w n y 5)$} & $\mathrm{C}$ & 8.80E-06 & na & & $\mathrm{d}($ wny2,2) & 0.105386 & 1.2726 \\
\hline & wny5(-1) & 0.002551 & 1 & & $\mathrm{~d}$ (wny6) & 0.196036 & 2.507426 \\
\hline \multirow[t]{3}{*}{$d($ wny6) } & $\mathrm{C}$ & 1.06E-05 & na & & $\mathrm{d}($ wny6,2) & 0.087827 & 1.707267 \\
\hline & wny6(-1) & 0.002009 & 1.045802 & & $\mathrm{~d}($ wny9(-1)) & 0.374786 & 2.074322 \\
\hline & $d($ wny 10) & 0.001357 & 1.045802 & & & & \\
\hline
\end{tabular}




\section{Modelling the Sectoral Structure of the Final Output}

The centered VIF amount to 1-1.5 for 13 variables and to 1.5-2.25 for the other 9 . Only in three cases it is larger, but it does not exceed 2.7. It seems reasonable, therefore, to admit that the collinearity syndrome does not significantly alter the SySw system.

5.2. According to the Breusch-Pagan-Godfrey test (Table 4), the probability for the rejection of heteroskedasticity hypothesis is significant in all cases.

Table 4

Breusch-Pagan-Godfrey Heteroskedasticity Test

\begin{tabular}{|c|c|c|c|c|c|c|c|c|c|}
\hline d(wny1) & $\begin{array}{l}\text { F- } \\
\text { statistic }\end{array}$ & 0.3673 & $\begin{array}{l}\text { Prob. } \\
F(2,17)\end{array}$ & 0.698 & $d($ wny6) & F-statistic & 1.2336 & $\begin{array}{l}\text { Prob. } \\
(2,17)\end{array}$ & 0.316 \\
\hline & $\begin{array}{l}\text { Obs*R- } \\
\text { squared }\end{array}$ & 0.8283 & $\begin{array}{l}\text { Prob. Chi- } \\
\text { Square(2) }\end{array}$ & 0.6609 & & $\begin{array}{l}\text { Obs*R- } \\
\text { squared }\end{array}$ & 2.5348 & \begin{tabular}{|l|} 
Prob. Chi- \\
Square(2)
\end{tabular} & 0.2816 \\
\hline & $\begin{array}{l}\text { Scaled } \\
\text { expl. SS }\end{array}$ & 0.7401 & $\begin{array}{l}\text { Prob. Chi- } \\
\text { Square(2) }\end{array}$ & 0.6907 & & $\begin{array}{l}\text { Scaled } \\
\text { expl. SS }\end{array}$ & 1.0414 & $\begin{array}{l}\text { Prob. Chi- } \\
\text { Square(2) }\end{array}$ & 0.5941 \\
\hline \multirow[t]{3}{*}{$d$ (wny2) } & $\begin{array}{l}\text { F- } \\
\text { statistic }\end{array}$ & 1.4749 & \begin{tabular}{|l|} 
Prob. \\
$F(2,16)$
\end{tabular} & 0.2583 & $d($ wny7) & F-statistic & 0.0205 & $\begin{array}{l}\text { Prob.F }(4,1 \\
4)\end{array}$ & 0.9991 \\
\hline & $\begin{array}{l}\text { Obs }{ }^{*} \mathrm{R}- \\
\text { squared }\end{array}$ & 2.9576 & $\begin{array}{l}\text { Prob. Chi- } \\
\text { Square(2) }\end{array}$ & 0.2279 & & $\begin{array}{l}\text { Obs*R- } \\
\text { squared }\end{array}$ & 0.1107 & $\begin{array}{l}\text { Prob. Chi- } \\
\text { Square(4) }\end{array}$ & 0.9985 \\
\hline & $\begin{array}{l}\text { Scaled } \\
\text { expl. SS }\end{array}$ & 2.4937 & $\begin{array}{l}\text { Prob. Chi- } \\
\text { Square(2) }\end{array}$ & 0.2874 & & $\begin{array}{l}\text { Scaled } \\
\text { expl. SS }\end{array}$ & 0.0879 & $\begin{array}{l}\text { Prob. Chi- } \\
\text { Square(4) }\end{array}$ & 0.9991 \\
\hline \multirow[t]{3}{*}{ d(wny3) } & $\begin{array}{l}\text { F- } \\
\text { statistic }\end{array}$ & 2.0411 & $\begin{array}{l}\text { Prob. } \\
F(2,17)\end{array}$ & 0.1605 & d(wny8) & F-statistic & 0.3716 & $\begin{array}{l}\text { Prob.F(2,1 } \\
7)\end{array}$ & 0.6951 \\
\hline & $\begin{array}{l}\text { Obs*R- } \\
\text { squared }\end{array}$ & 3.8726 & $\begin{array}{l}\text { Prob. Chi- } \\
\text { Square(2) }\end{array}$ & 0.1442 & & $\begin{array}{l}\text { Obs*R- } \\
\text { squared }\end{array}$ & 0.8378 & $\begin{array}{l}\text { Prob. Chi- } \\
\text { Square(2) }\end{array}$ & 0.6578 \\
\hline & $\begin{array}{l}\text { Scaled } \\
\text { expl. SS }\end{array}$ & 2.1847 & $\begin{array}{l}\text { Prob. Chi- } \\
\text { Square(2) }\end{array}$ & 0.3354 & & $\begin{array}{l}\text { Scaled } \\
\text { expl' SS }\end{array}$ & 0.3734 & $\begin{array}{l}\text { Prob. Chi- } \\
\text { Square(2) }\end{array}$ & 0.8297 \\
\hline \multirow[t]{3}{*}{$d($ wny4) } & $\begin{array}{l}\mathrm{F}- \\
\text { statistic }\end{array}$ & 0.6824 & $\begin{array}{l}\text { Prob. } \\
F(3,16)\end{array}$ & 0.5756 & d(wny9) & F-statistic & 0.2003 & $\begin{array}{l}\text { Prob.F }(2,1 \\
7)\end{array}$ & 0.8204 \\
\hline & $\begin{array}{l}\text { Obs }{ }^{*} \mathrm{R}- \\
\text { squared }\end{array}$ & 2.2688 & $\begin{array}{l}\text { Prob. Chi- } \\
\text { Square(3) }\end{array}$ & 0.5185 & & $\begin{array}{l}\text { Obs*R- } \\
\text { squared }\end{array}$ & 0.4605 & $\begin{array}{l}\text { Prob. Chi- } \\
\text { Square(2) }\end{array}$ & 0.7943 \\
\hline & $\begin{array}{l}\text { Scaled } \\
\text { expl. SS }\end{array}$ & 1.4144 & $\begin{array}{l}\text { Prob. Chi- } \\
\text { Square(3) }\end{array}$ & 0.7022 & & $\begin{array}{l}\text { Scaled } \\
\text { expl. SS }\end{array}$ & 0.3738 & $\begin{array}{l}\text { Prob. Chi- } \\
\text { Square(2) }\end{array}$ & 0.8295 \\
\hline \multirow[t]{3}{*}{ d(wny5) } & $\begin{array}{l}\text { F- } \\
\text { statistic }\end{array}$ & 0.0282 & $\begin{array}{l}\text { Prob. } \\
F(1,18) \\
\end{array}$ & 0.8684 & $d$ (wny10) & F-statistic & 0.275 & $\begin{array}{l}\text { Prob. } F(5,1 \\
3)\end{array}$ & 0.9187 \\
\hline & $\begin{array}{l}\text { Obs }{ }^{*} \mathrm{R}- \\
\text { squared }\end{array}$ & 0.0313 & $\begin{array}{l}\text { Prob. Chi- } \\
\text { Square(1) }\end{array}$ & 0.8595 & & $\begin{array}{l}\text { Obs*R- } \\
\text { squared }\end{array}$ & 1.8176 & $\begin{array}{l}\text { Prob. Chi- } \\
\text { Square(5) }\end{array}$ & 0.8738 \\
\hline & $\begin{array}{l}\text { Scaled } \\
\text { expl. SS }\end{array}$ & 0.0256 & $\begin{array}{l}\text { Prob. Chi- } \\
\text { Square(1) }\end{array}$ & 0.8728 & & $\begin{array}{l}\text { Scaled } \\
\text { expl. SS }\end{array}$ & 0.8202 & $\begin{array}{l}\text { Prob. Chi- } \\
\text { Square(5) }\end{array}$ & 0.9757 \\
\hline
\end{tabular}

5.3. The OLS residuals were submitted to both unit root tests $A D F$ and $P P$, in all the available options for exogenous conditions (Table 5). 
Unit Root Tests for Residuals (res)

\begin{tabular}{|c|c|c|c|c|c|}
\hline Series & Exogenous & ADF & & PP & \\
\hline & & t-Statistic & Prob. & Adj. t-Stat & Prob. \\
\hline \multirow[t]{3}{*}{ reswny1 } & None & -4.64555 & 0.0001 & -4.64555 & 0.0001 \\
\hline & Constant & -4.51013 & 0.0024 & -4.51013 & 0.0024 \\
\hline & Constant, linear trend & -4.4027 & 0.0128 & -4.4027 & 0.0128 \\
\hline \multirow[t]{3}{*}{ reswny2 } & None & -3.83592 & 0.0007 & -3.83146 & 0.0007 \\
\hline & Constant & -3.72723 & 0.013 & -3.70252 & 0.0137 \\
\hline & Constant, linear trend & -3.69561 & 0.0496 & -3.85037 & 0.0376 \\
\hline \multirow[t]{3}{*}{ reswny3 } & None & -4.32818 & 0.0002 & -4.67667 & 0.0001 \\
\hline & Constant & -4.20564 & 0.0046 & -4.4892 & 0.0025 \\
\hline & Constant, linear trend & -4.10338 & 0.0226 & -4.73247 & 0.0068 \\
\hline \multirow[t]{3}{*}{ reswny4 } & None & -4.4433 & 0.0001 & -4.4433 & 0.0001 \\
\hline & Constant & -4.3169 & 0.0036 & -4.3169 & 0.0036 \\
\hline & Constant, linear trend & -4.20967 & 0.0185 & -4.20926 & 0.0185 \\
\hline \multirow[t]{3}{*}{ reswny5 } & None & -5.02309 & 0 & -5.9537 & 0 \\
\hline & Constant & -4.88165 & 0.0011 & -5.72604 & 0.0002 \\
\hline & Constant, linear trend & -4.08859 & 0.0244 & -5.15 & 0.0031 \\
\hline \multirow[t]{3}{*}{ reswny6 } & None & -5.07258 & 0 & -5.11736 & 0 \\
\hline & Constant & -4.94774 & 0.001 & -4.9896 & 0.0009 \\
\hline & Constant, linear trend & -3.17295 & 0.1244 & -14.2635 & 0.0001 \\
\hline \multirow[t]{3}{*}{ reswny7 } & None & -5.5984 & 0 & -5.47931 & 0 \\
\hline & Constant & -5.42818 & 0.0004 & -5.32661 & 0.0005 \\
\hline & Constant, linear trend & -5.26999 & 0.0027 & -5.18459 & 0.0032 \\
\hline \multirow[t]{3}{*}{ reswny8 } & None & -2.92002 & 0.0059 & -2.92002 & 0.0059 \\
\hline & Constant & -2.84165 & 0.0713 & -2.84165 & 0.0713 \\
\hline & Constant, linear trend & -2.7104 & 0.2434 & -2.7104 & 0.2434 \\
\hline \multirow[t]{3}{*}{ reswny9 } & None & -3.75772 & 0.0008 & -3.78099 & 0.0007 \\
\hline & Constant & -3.66193 & 0.0142 & -3.68954 & 0.0134 \\
\hline & Constant, linear trend & -3.4935 & 0.0689 & -3.53176 & 0.0644 \\
\hline \multirow[t]{3}{*}{ reswny10 } & None & -3.95378 & 0.0005 & -3.94569 & 0.0005 \\
\hline & Constant & -3.83568 & 0.0105 & -3.82305 & 0.0107 \\
\hline & Constant, linear trend & -3.71337 & 0.048 & -3.69565 & 0.0496 \\
\hline
\end{tabular}

5.4. Finally, as for the OLS residuals, the BDS (Brock-Dechert-Scheinkman) test was applied as a powerful tool to identify an extended spectrum of possible serial correlations (Annex 4). Five embedding dimensions (2, 3, 4, 5, and 6) and three options related to the distance (fraction of pairs, the standard deviations, and the fraction of range) were adopted. The $p$-value for the tested null hypothesis was estimated for both the sample data (normal probability), and their random repetitions (bootstrap probability). Consequently, $30 \mathrm{p}$-values were computed for each wny. Grouped into four categories (below $0.05 ; 0.05-0.1 ; 0.1-0.25$; and $0.25-1$ ), these 300 resultant $p$-values are represented in Graph BDSn for normal probability and Graph BDSb for the bootstrap. 


\section{GraphBDSn}

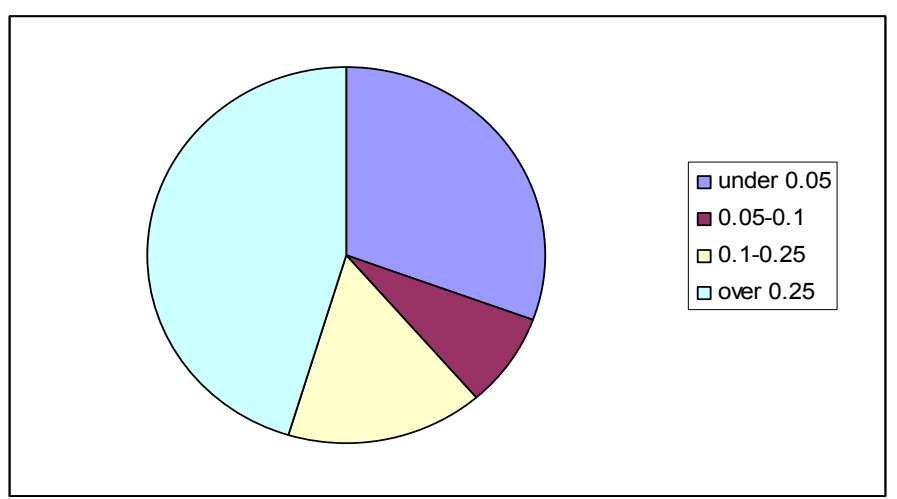

\section{GraphBDSb}

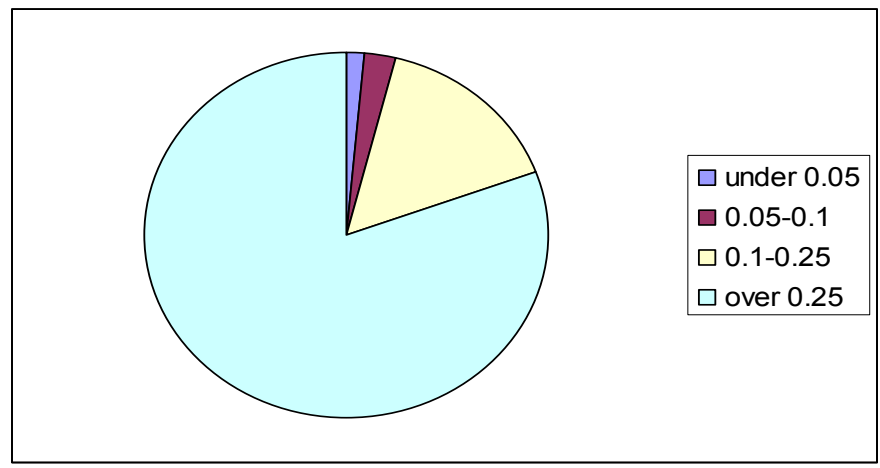

Overall, $63 \%$ of the BDS p-values exceed 0.25 and almost $16 \%$ are situated between 0.1 and 0.25 . The distribution of bootstrap p-values - considered more relevant for small samples, as in our case - confirms clearly the absence of the serial correlation in the reswny $y_{i}$ series (81\% over 0.25 and $15 \%$ in the group $0.1-0.25$ ).

Summarizing, the tests for collinearity, heteroskedasticity, stationarity and serial correlation of residuals confirm the adequacy of the OLS estimations.

6. Nevertheless, a question must be supplementarily examined. Based on the OLS estimators, wny $\mathrm{y}_{\mathrm{i}}$ were projected for the following five years after statistical sampling.

This operation was developed in two stages.

- During the first stage, the econometric relationships were computed, obtaining

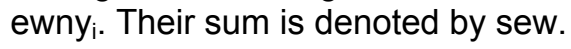

- In the second stage, the ewny $y_{i}$ were multiplied by $1 /$ sew in order to observe the compulsory equality of $\Sigma w n y_{i}=1$.

The resultant values are presented in Table 6. 
Table 6

Forecasted OLS Values for 5 Post-Sampling Years

\begin{tabular}{|l|c|c|c|c|c|}
\hline Year & 1 & 2 & 3 & 4 & 5 \\
\hline wny1 & 0.060512 & 0.06752 & 0.061612 & 0.0724 & 0.056283 \\
\hline wny2 & -0.02993 & -0.02851 & -0.02752 & -0.02638 & -0.02639 \\
\hline wny3 & 0.020214 & 0.025767 & 0.018514 & 0.031848 & 0.013504 \\
\hline wny4 & 0.057528 & 0.058748 & 0.051379 & 0.057018 & 0.043956 \\
\hline wny5 & 0.026349 & 0.028413 & 0.025871 & 0.030301 & 0.024045 \\
\hline wny6 & 0.037573 & 0.062204 & 0.013424 & 0.082552 & -0.02279 \\
\hline wny7 & -0.07169 & -0.06186 & -0.07967 & -0.05446 & -0.09378 \\
\hline wny8 & 0.174453 & 0.182141 & 0.161686 & 0.190341 & 0.148574 \\
\hline wny9 & 0.112444 & 0.119088 & 0.108231 & 0.126818 & 0.101799 \\
\hline wny10 & 0.612553 & 0.546485 & 0.666469 & 0.489554 & 0.754803 \\
\hline Sum & 1 & 1 & 1 & 1 & 1 \\
\hline
\end{tabular}

The registered volatility for some wny $y_{i}$ cannot be neglected. Besides, beginning in the sixth year, the forecasts even induce doubtful values. Consequently, an alternative solution was also investigated.

\section{Moving Average Attempt}

To find an alternative solution, the moving average method was considered as a possible competitor. However, in which variant should the moving average be: simple or weighted? In economics, the recent lags of time series are involved more frequently than those that are remote. This means an implicit preference for the weighted moving average. We shall apply it to the so-called Fisher version (Fisher, 1937).

1. As it is known, the weights of different sample observations included in computations depend on the adopted length (number of terms, denoted by $k$ ) of the moving average. According to Fisher's formula, beginning with the 13-th anterior observation, such a weight becomes insignificant (lower than 1\%). This is why the searched interval in the present paper is comprised between 2 and 12 terms (Annex 5). Even under this limitation, the range of possible options remains large enough (11 variants). Usually, the actual choice of the moving average length is based on empirical reasons. In our opinion, however, some rules in this sense could be established.

1.1. Among them, the degree at which the properties of the given statistical series are reflected in the estimated corresponding moving averages $\left(\mathrm{ma}_{\mathrm{k}}\right)$ must be taken into consideration. Our trials have showed that - for such a purpose - the information criterion $\left(\mathrm{IC}_{\mathrm{k}}\right)$ could be useful. There are several such measures, the most frequently used are Akaike - AIC (Akaike, 1973, 1974), SIC - Schwarz (Schwarz, 1978), and Hannan-Quinn - HQC (Hannan and Quinn, 1979). An extensive mathematical and interpretative background for these statistical tools can be found in Burnham and Anderson, 2002 and 2004; Gagne and Dayton, 2002; Lukacs et al., 2007, Claeskens and Hjort, 2008. As a discussion proposal, our applicative procedure will be exemplified involving only $\mathrm{AIC}_{\mathrm{k}}$ variant in the following numerical determination: 
Modelling the Sectoral Structure of the Final Output

$$
A I C=\left(\frac{1}{n} \sum_{t=1}^{n} u_{t}^{2}\right) * e^{\frac{2(k+1)}{n}}
$$

where: $\mathrm{n}$ is the sample size, $\mathrm{u}$ is the differences between primary data and the corresponding moving average results, and $\mathrm{k}$ is the number of terms included in computations.

1.2. Extrapolating the series examined here, at one time, the moving average generates very small first-order successive differences (under a given conventionally established level), which could be interpreted as a symptom that the given computational algorithm ceases to reflect adequately the original data. Consequently, the post-sampling interval in which the results of the moving average do not yet reach the mentioned treshold can be considered as a sort of temporal relevance of the examined procedure (denoted by $\tau_{k}$ ). If $n$ is the last sample observation, then $\tau_{k}=(n+1)$, $(n+2), \ldots,(n+m)$. In practice, it is necessary to define numerically the conventional threshold, to which the temporal relevance of the compared moving average lengths is defined. In principle, a higher $\tau$ could be considered as a sign of a more adequate reflection of the primary series.

1.3. The behavior of calculated data within the $\tau_{k}$ interval is also of interest. Which of the resulted series reproduces the original information more faithfully? The one that is relatively flattened or the other that is more volatile? In our opinion, it is the second, as both the involved methods originate from the same statistics and their only difference is in the number of terms included in the moving average. The coefficient of variation that was determined for the post-sampling estimated data (denoted by $\mathrm{CV}_{\mathrm{k}}$ ) could approximate such a structural inertiality of extrapolation.

2. In the case of wny series, the above mentioned parameters $-\mathrm{AIC}_{\mathrm{k}}, \tau_{\mathrm{k}}$, and $\mathrm{CV}_{\mathrm{k}}$ were determined for all compared lengths (namely $k=2,3 \ldots 12$ ). Annex 6 presents the results. In order to facilitate their interpretation, we adopt a transformed variant that is more familiar to economists.

2.1. Thus, $A I C_{k}$ is recomputed as an information criterion index, denoted by $I C I_{k}$. If $\mathrm{AIC}_{\max }$ represents the maximum $\mathrm{AIC}$ among the $\mathrm{k}$ registered values, then:

$$
I C I_{k}=1-\frac{A I C_{k}}{A I C_{\max }}
$$

For positive values (as in our application), this index observes the inequality $0 \leq|C|_{k} \leq 1$. A higher $\mathrm{ICl}_{\mathrm{k}}$ would be interpreted as better reproducing the respective statistical data, and vice-versa. Table 7 details the information criterion indices for all wny.

Table 7

Informational Criterion Indices

\begin{tabular}{|c|c|c|c|c|c|c|c|c|c|c|}
\hline $\begin{array}{c}\text { Number } \\
\text { of terms }\end{array}$ & Wny1 & wny2 & wny3 & wny4 & wny5 & wny6 & wny7 & Wny8 & wny9 & wny10 \\
\hline 2 & 0.98676 & 0.93491 & 0.8543 & 0.99645 & 0.96434 & 0.98316 & 0.98316 & 0.99527 & 0.98843 & 0.98979 \\
\hline 3 & 0.98807 & 0.83505 & 0.66041 & 0.99016 & 0.90446 & 0.94253 & 0.94253 & 0.9873 & 0.96336 & 0.96779 \\
\hline 4 & 0.9793 & 0.73139 & 0.50081 & 0.9801 & 0.83302 & 0.91632 & 0.91632 & 0.98112 & 0.91016 & 0.94969 \\
\hline 5 & 0.96125 & 0.57673 & 0.6256 & 0.96462 & 0.81457 & 0.88755 & 0.88755 & 0.96709 & 0.82559 & 0.92217 \\
\hline
\end{tabular}




\begin{tabular}{|c|l|l|l|l|l|l|l|l|l|l|}
\hline $\begin{array}{c}\text { Number } \\
\text { of terms }\end{array}$ & Wny1 & wny2 & wny3 & wny4 & wny5 & wny6 & wny7 & Wny8 & wny9 & wny10 \\
\hline 6 & 0.94511 & 0.65523 & 0.48987 & 0.94415 & 0.69562 & 0.81553 & 0.81553 & 0.94597 & 0.69287 & 0.88338 \\
\hline 7 & 0.9115 & 0.70766 & 0.30351 & 0.91632 & 0.5077 & 0.67274 & 0.67274 & 0.9172 & 0.54805 & 0.82346 \\
\hline 8 & 0.85808 & 0.63068 & 0.12138 & 0.89422 & 0.50896 & 0.55237 & 0.55237 & 0.86979 & 0.41354 & 0.7411 \\
\hline 9 & 0.77393 & 0.54011 & 0 & 0.83951 & 0.35864 & 0.45156 & 0.45156 & 0.79279 & 0.44329 & 0.6269 \\
\hline 10 & 0.64295 & 0.22413 & 0.70702 & 0.71165 & 0.07761 & 0.18299 & 0.18299 & 0.66365 & 0.38815 & 0.39487 \\
\hline 11 & 0.41296 & 0 & 0.60981 & 0.46113 & 0 & 0 & 0 & 0.43742 & 0.16785 & 0.10126 \\
\hline 12 & 0 & 0.29144 & 0.35344 & 0 & 0.36579 & 0.22732 & 0.22732 & 0 & 0 & 0 \\
\hline
\end{tabular}

It must be noted that, generally, the informational criterion index preponderantly decreases under increasing number of terms used in the Fisher linear moving average. Only for two series - wny2 and wny 3 - it fluctuates.

2.2. In the case of the second property, a temporal persistence index $\left(\operatorname{TPI}_{k}\right)$ is approximated by

$$
T P I_{k}=\frac{\tau_{k}}{\tau_{\max }}
$$

where: $\tau_{\max }$ is the maximum $\tau$

This index also observes the restriction $0 \leq \mathrm{TPI}_{k} \leq 1$.

In our application, we use as a limit of the post-sampling extrapolation $€=0.0001$ for at least five successive values. If $\mathrm{ma}_{\mathrm{j}}$ represent the moving average estimations, $\epsilon$ is defined as follows: $\left.\epsilon=\left(\left(m_{j} / m_{j-1}-1\right)^{\wedge} 2\right)^{\wedge} 0.5 ;(n+1) \leq j \leq n+m\right)$. The obtained results for the temporal relevance indices are given in Table 8.

Table 8

Temporal Relevance Indices

\begin{tabular}{|c|c|c|c|c|c|c|c|c|c|c|}
\hline $\begin{array}{c}\text { Number of } \\
\text { terms }\end{array}$ & wny1 & wny2 & wny3 & wny4 & wny5 & wny6 & wny7 & wny8 & wny9 & wny10 \\
\hline 2 & 0.27273 & 0.42857 & 0.42857 & 0.28571 & 0.35294 & 0.35294 & 0.27273 & 0.21053 & 0.25 & 0.23529 \\
\hline 3 & 0.36364 & 0.42857 & 0.5 & 0.33333 & 0.33333 & 0.35294 & 0.31818 & 0.36842 & 0.375 & 0.23529 \\
\hline 4 & 0.40909 & 0.5 & 0.64286 & 0.42857 & 0.42857 & 0.41176 & 0.40909 & 0.47368 & 0.4375 & 0.29412 \\
\hline 5 & 0.5 & 0.64286 & 0.64286 & 0.52381 & 0.52381 & 0.52941 & 0.45455 & 0.57895 & 0.5 & 0.47059 \\
\hline 6 & 0.59091 & 0.71429 & 0.71429 & 0.57143 & 0.57143 & 0.58824 & 0.54545 & 0.68421 & 0.5625 & 0.52941 \\
\hline 7 & 0.63636 & 0.78571 & 0.78571 & 0.66667 & 0.66667 & 0.64706 & 0.5 & 0.73684 & 0.5625 & 0.58824 \\
\hline 8 & 0.72727 & 0.85714 & 0.85714 & 0.71429 & 0.71429 & 0.88235 & 0.68182 & 0.84211 & 0.625 & 0.64706 \\
\hline 9 & 0.77273 & 0.92857 & 0.92857 & 0.80952 & 0.80952 & 0.88235 & 0.77273 & 0.89474 & 0.6875 & 0.70588 \\
\hline 10 & 0.86364 & 1 & 1 & 0.85714 & 0.85714 & 0.88235 & 0.81818 & 1 & 0.75 & 0.82353 \\
\hline 11 & 0.90909 & 0.92857 & 0.92857 & 0.95238 & 0.95238 & 1 & 0.90909 & 0.89474 & 0.875 & 0.88235 \\
\hline 12 & 1 & 1 & 1 & 1 & 1 & 0.94118 & 1 & 0.94737 & 1 & 1 \\
\hline
\end{tabular}




\section{Modelling the Sectoral Structure of the Final Output}

Without some minor deviations, the temporal relevance indices, in all cases, are positively correlated with the number of terms implied in the Fisher linear moving average, which means a comparatively converse situation with $\mathrm{ICl}$.

2.3. We shall proceed in a similar way to the case of the third discussed property. If mma represents the mean of the resultant moving averages during $\mathrm{T}$, and $\mathrm{T}$ includes $\mathrm{m}$ values, then the coefficient of variation $\left(\mathrm{CV}_{\mathrm{T}}\right)$ is approximated by

$$
C V_{\tau}=\sqrt{\frac{\sum_{\tau}\left(\frac{m a_{\tau}}{m m a}-1\right)^{2}}{m}}
$$

On this basis, a structural inertiality index $\left(\mathrm{SII}_{\mathrm{K}}\right)$ can be determined:

$$
S I I_{k}=\frac{C V_{k}}{C V_{\max }}
$$

where: $\mathrm{CV}_{\max }$ is the maximum $\mathrm{CV}_{\mathrm{T}}$. Again, the limits $0 \leq S \|_{\mathrm{K}} \leq 1$ are valid.

For the here examined wny $y_{i}$ series, these indices are given in Table 9.

Table 9

\section{Structural Inertiality Indices}

\begin{tabular}{|c|c|c|c|c|c|c|c|c|c|c|}
\hline $\begin{array}{c}\text { Number of } \\
\text { terms }\end{array}$ & wny1 & wny2 & wny3 & wny4 & wny5 & wny6 & wny7 & wny8 & wny9 & wny10 \\
\hline 2 & 0.0852 & 0.00436 & 0.00415 & 0.01202 & 0.0049 & 0.00451 & 0.01102 & 1 & 0.88905 & 0.66662 \\
\hline 3 & 0.26458 & 0.68798 & 0.34336 & 1 & 0.3392 & 0.94549 & 0.58212 & 0.37575 & 0.66656 & 1 \\
\hline 4 & 0.62947 & 0.61167 & 0.00876 & 0.03815 & 0.02132 & 0.84091 & 0.01807 & 0.0239 & 0.59239 & 0.88901 \\
\hline 5 & 0.87703 & 0.50056 & 0.49916 & 0.05121 & 0.02093 & 0.6884 & 0.42423 & 0.02881 & 0.72707 & 0.5456 \\
\hline 6 & 0.97483 & 0.63539 & 0.63368 & 0.61693 & 0.01664 & 0.8741 & 0.35934 & 0.03134 & 0.82037 & 0.61561 \\
\hline 7 & 1 & 0.59015 & 0.58862 & 0.07759 & 0.38731 & 0.81237 & 1 & 0.03333 & 0.95229 & 0.5717 \\
\hline 8 & 0.96483 & 0.68838 & 0.68692 & 0.50556 & 0.50864 & 0.23136 & 0.29387 & 0.03292 & 1 & 0.62536 \\
\hline 9 & 0.96491 & 0.64771 & 0.64661 & 0.09965 & 0.47895 & 0.43266 & 0.04925 & 0.03199 & 0.94132 & 0.58871 \\
\hline 10 & 0.96113 & 0.72409 & 0.72327 & 0.43139 & 1 & 0.77187 & 0.25403 & 0.02941 & 0.98287 & 0.50789 \\
\hline 11 & 0.98401 & 0.96255 & 0.96216 & 0.11167 & 0.81383 & 0.55163 & 0.08336 & 0.4398 & 0.80071 & 0.484 \\
\hline 12 & 0.90759 & 1 & 1 & 0.37717 & 0.61652 & 1 & 0.08742 & 0.53326 & 0.72811 & 0.45529 \\
\hline
\end{tabular}

In comparison with $\mathrm{ICl}_{\mathrm{k}}$ and $\mathrm{TPI}_{\mathrm{k}}$, the structural inertiality index $\left(\mathrm{SI} \mathrm{I}_{\mathrm{k}}\right)$ provides a more complicated picture. Graph SII1 refers to the series wny1-wny5. The situation does not change significantly for the series wny6-wny10, described in the Graph SII2. 
Graph SII1

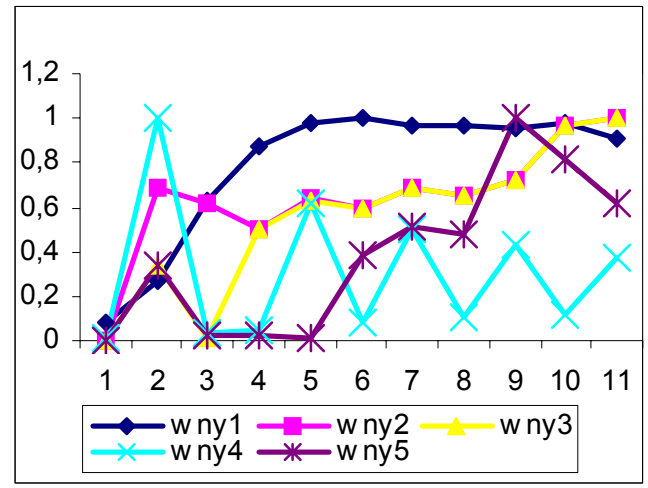

Graph SII2

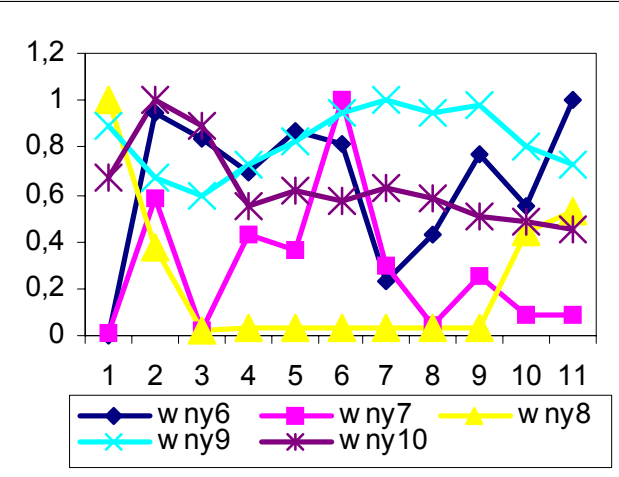

2.4. The indices of informational criterion, temporal relevance, and structural inertiality provide, therefore, contradictory signals. Therefore, based on $\mathrm{ICl}_{\mathrm{k}}, \mathrm{TPI}_{\mathrm{k}}$, and $\mathrm{SII}_{\mathrm{k}}$ as individual parameters, it would be difficult to choose consistently an optimal length of the moving average. Hereinafter, we shall try to aggregate them into a single composite selecting length index $\left(S L I_{k}\right)$.

3. For such a goal, it is necessary to define the summation weights $s 1_{i}$ (for $I C l_{k}$ ), $s 2$ i (for $\mathrm{TPI}_{\mathrm{k}}$ ), and $\mathrm{s} 3_{\mathrm{i}}$ (for $S \mathrm{II}_{\mathrm{k}}$ ), under the restrictions $0 \leq \mathrm{s} 1_{\mathrm{i}} \leq 1,0 \leq \mathrm{s} 2_{\mathrm{i}} \leq 1,0 \leq \mathrm{s} 3_{\mathrm{i}} \leq 1$, and $s 1_{i}+s 2_{i}+s 3_{i}=1$; obviously, $i$ refers to the corresponding wny $y_{i}$ series $(i=1,2 \ldots 10)$.

3.1. In order to estimate these summation weights, for each series $w_{n} y_{i}$, the following system is built:

$$
\begin{gathered}
S L I_{k i}=s 1_{i} * I C I_{k i}+s 2_{i} * T P I_{k i}+s 3_{i} * S I I_{k i} \quad \mathrm{k}=2,3 \ldots 12 \\
M S L I_{i}=\frac{1}{11} \sum_{k} S L I_{k i} \\
V S L_{i}=\frac{1}{11}\left[\sum_{k}\left(S L I_{k i}-M S L I_{i}\right)^{2}\right] \\
S T D_{i}=\sqrt{V S L_{i}}
\end{gathered}
$$

Our proposal is to solve the system by adding the minimization of the standard deviation as an objective function. The resultant summation weights $s$ by this procedure are detailed in Table 10.

Table 10

\section{Estimated Summation Weights S}

\begin{tabular}{|l|c|c|c|c|c|}
\hline Series & wyn1 & wyn2 & wyn3 & wyn4 & wyn5 \\
\hline ICI (s1) & 0.42668 & 0.42953 & 0.41179 & 0.38829 & 0.43897 \\
\hline TPI (s2) & 0.57332 & 0.37633 & 0.58821 & 0.51083 & 0.37517 \\
\hline SII (s3) & 0 & 0.19414 & 0.00000 & 0.10089 & 0.18587 \\
\hline Series & wyn6 & wyn7 & wyn8 & wyn9 & wny10 \\
\hline ICI (s1) & 0.38974 & 0.38227 & 0.32074 & 0.34398 & 0.22502 \\
\hline TPI (s2) & 0.54771 & 0.56507 & 0.42645 & 0.49398 & 0.46296 \\
\hline SII (s3) & 0.06255 & 0.05266 & 0.25281 & 0.16204 & 0.31202 \\
\hline
\end{tabular}


Modelling the Sectoral Structure of the Final Output

3.2. Using these summation weights, the selecting length indices $\left(S L I_{k}\right)$ were determined for all wny (Annex 7). These are plotted on Graph SLI1 for wny1-wny5.

According to the proposed methodology, therefore, the preferable lengths of a Fisher weighted moving average would be:

- 8 terms for wny1, wny2, and wny4;

- 10 terms for wny3; and

- 12 terms for wny5.

The selecting length indices for wny6-wny10 are presented in the Graph SLI2.

Graph SLI1

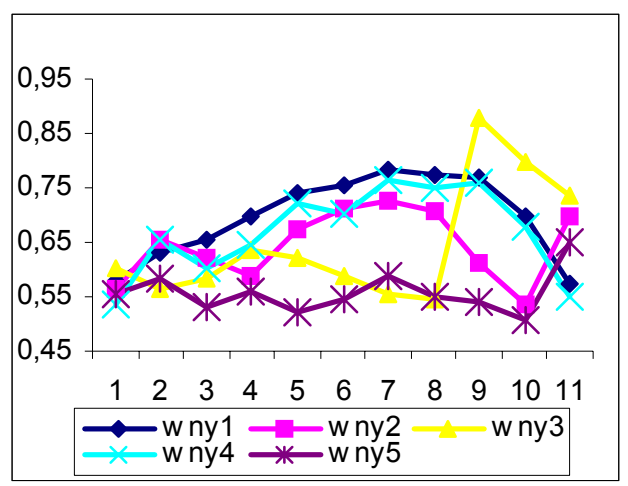

Graph SLI2

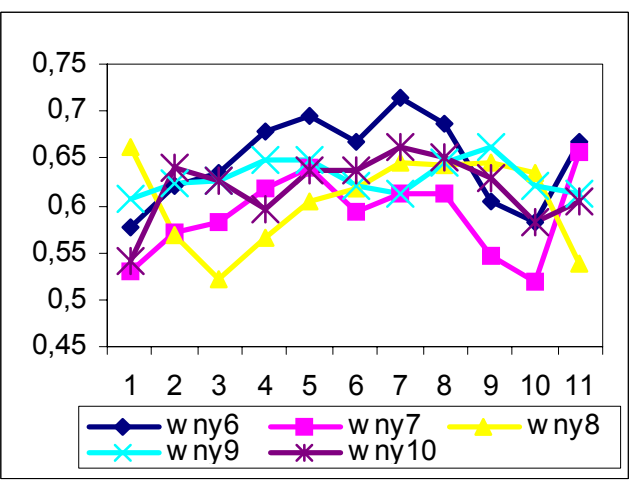

Now, the moving averages with:

- 8 terms for wny 6 and wny 10 ;

- 12 terms for wny7;

- 2 terms for wny8; and

- 10 terms for wny9 are in a better position.

3.3. Similarly to the OLS application, the moving averages were also extended five years after sampling. The restriction $\Sigma$ wnyi $=1$ was applied similarly to the previous exercise.

Table 11

Forecasted wny $y_{i}$ by Moving Average for Five Post-Sampling Years

\begin{tabular}{|l|c|c|c|c|c|}
\hline \multicolumn{1}{|c|}{$\mathrm{t}$} & 1 & 2 & 3 & 4 & 5 \\
\hline wny1 & 0.071049 & 0.068838 & 0.067093 & 0.065959 & 0.065802 \\
\hline wny2 & -0.02955 & -0.03001 & -0.03026 & -0.03047 & -0.03054 \\
\hline wny3 & 0.022274 & 0.022474 & 0.022563 & 0.022587 & 0.022539 \\
\hline wny4 & 0.061389 & 0.060845 & 0.060416 & 0.060091 & 0.059997 \\
\hline wny5 & 0.030815 & 0.031238 & 0.031459 & 0.031466 & 0.031363 \\
\hline wny6 & 0.054259 & 0.055117 & 0.055817 & 0.056259 & 0.056392 \\
\hline wny7 & -0.0567 & -0.05813 & -0.05898 & -0.05969 & -0.06002 \\
\hline wny8 & 0.187372 & 0.184453 & 0.183708 & 0.183274 & 0.183304 \\
\hline wny9 & 0.117852 & 0.118737 & 0.119181 & 0.11953 & 0.119601 \\
\hline wny10 & 0.541248 & 0.546442 & 0.549005 & 0.550994 & 0.551564 \\
\hline Sum & 1 & 1 & 1 & 1 & 1 \\
\hline
\end{tabular}


As expected, the projected evolution is more stable if compared with the OLS estimations.

\section{Some concluding remarks}

1. Under a given A matrix, the structure of the economy - represented by its sectoral output - can be approximated by starting from the I-O quadrant of resource utilization (demand-side approach), or from the sectoral final output vector (supply-side approach).

If we have macroeconomic estimations for final (private and public) consumption, gross fixed capital formation, inventory changes, export, import, and gross value added, sectoral distributions are necessary in order to determine the structure of the output:

- for six mentioned aggregates in the case of demand-side approach; and

- only for final outputs, for the supply-side approach.

If the modelling objective refers preponderantly to the sectoral structure of output, then the supply-side approach seems to be more accessible.

2. In both cases, we can involve expert exogenous data or different statistical procedures. In terms of statistical procedures, the present paper illustrates, on the one hand, the applicability of the regression technique and, on the other hand, of the linear weighted average (Fisher version). As a primary database, the Romanian I-O tables for 1989-2009 aggregated into 10 sectors were used.

3. The econometric specification referred to the weights of these sectors in the final output of the economy. The retained relationships were submitted to a large battery of tests concerning collinearity, heteroskedasticity, stationarity, and serial correlation. Several estimating techniques were also involved.

4. The paper sketches - as a discussion proposal - a methodology for the selection of an optimal number of terms included in the moving average. This attempt takes into consideration the measure in which the resultant values reproduce the properties of the original statistical series. Further researches are necessary in this field.

5. Our application shows that - concerning the dynamic behavior of the estimated indicators - the econometric technique seems to be more sensitive than the moving average. Consequently, their possible combinations could be taken into consideration.

\section{References}

Akaike, H. 1973. Information Theory and an Extension of the Maximum Likelihood Principle. In: Petrov B.N. and Csaki F. (eds.), $2^{\text {nd }}$ International Symposium on Information Theory, Budapest: Akadémiai Kiadó, pp. 267-281. (Reproduced in Breakthroughs in Statistics, Vol. I, Foundations and Basic Theory, S. Kotz and N.L. Johnson eds., Springer-Verlag, New York, (1992) 610-624. 
Modelling the Sectoral Structure of the Final Output

Akaike, H., 1974. A New Look at the Statistical Model Identification. IEEE Transactions on Automatic Control, 19(6), pp. 716-723.

Burnham, K.P. and Anderson, D.R., 2002. Model Selection and Multimodel Inference: A Practical Information-Theoretical Approach, Second Edition. New York: Springer-Verlag.

Burnham, K.P. and Anderson, D.R., 2004. Multimodel Inference: Understanding AIC and BIC in Model Selection. Sociological Methods \& Research, November 2004 33: 261-304, 2004 Sage Publications. Available at: $<$ http://www.sortie-

nd.org/Ime/Statistical\%20Papers/Burnham_and_Anderson_2004_Mult imodel_Inference.pdf>. [Accessed 14 march 2013]

Claeskens, G. and N. L. Hjort 2008. Model Selection and Model Averaging. Cambridge Series in Statistical and Probabilistic Mathematics, Cambridge University Press, 312 pp.

Dobrescu, E., 2006. Integration of Macroeconomic Behavioural Relationships and the Input-Output Block (Romanian Modelling Experience). Presented at the International Conference on Policy Modelling (Ecomod 2006), Hong Kong, June 28-30. Available at: <http://www.ecomod.org/files/papers/1564.pdf>.

Dobrescu, E., 2009. Measuring the Interaction of Structural Changes with Inflation. Romanian Journal of Economic Forecasting, Supplement, 96 pgs.

Dobrescu, E. Gaftea, V. and Scutaru, C., 2010. Using the Leontief Matrix to Estimate the Impact of Investments Upon the Global Output. Romanian Journal of Economic Forecasting, 13(2), pp. 176-187.

Fisher Irving, 1937. Note on a Short-Cut Method for Calculating Distributed Lags. Bulletin de l'Institut International de Statistique, 29, Part 3, The Hague, 323-327. Cited in Maddala, G.S., 2001. Introduction to Econometrics, $3^{\text {rd }}$ Edition, Wiley, pp. 397-398.

Gagne, P. and Dayton, C.M., 2002. Best Regression Model Using Information Criteria. Journal of Modern Applied Statistical Methods, 1(2), pp.279-488. Available at: <http://education.umd.edu/EDMS/fac/Dayton/Gagne.pdf> [Accessed 14 march 2013].

Hannan, E.J. and Quinn, B.G., 1979. The Determination of the Order of an Autoregression. Journal of the Royal Statistical Society, Series B (Methodological), 41(2), pp. 190-195.

Jula, D. and Jula, N.M., 2012. Prognoza economica. Bucureşti: Editura Mustang.

Leontief, W.W., 1986. Input-Output Economics. Oxford University Press, Second Edition, $436 \mathrm{pp}$.

Lukacs, P.M. et. al., 2007. Concerns regarding a call for pluralism of information theory and hypothesis testing. Journal of Applied Ecology, 44, pp. 456-460.

Miller, R.E. and Blair, P.D., 2009. Input-Output Analysis: Foundations and Extensions. Cambridge University Press, Edition 2. 
National Commission for Prognosis, 2012.: Data Base of the Macromodel-Dobrescu from the Project "Strengthening the institutional capacity in evaluating and formulating of macroeconomic policies for economic convergence with EU within the National Commission for Prognosis", SMIS code 27153.

National Commission for Prognosis, 2013. Emilian Dobrescu - "Technical Report Macromodel of the Romanian Economy (2012 Version) - Integrated System". Project "Strengthening the institutional capacity in evaluating and formulating of macroeconomic policies for economic convergence with EU within the National Commission for Prognosis", SMIS code 27153.

NIS - TEMPO, 2012. Input-Output Tables. Available at: $<$ http://statistici.insse.ro/shop/?page=search\&lang=ro>.

Schwarz, G., 1978. Estimating the Dimension of a Model. The Annals of Statistics 1978, 6(2), pp.461-464.

Stone, R., 1961. Input-Output and National Accounts. Published by the Organisation for European Economic Co-operation, 204 pp.

United Nations, 1999. Handbook of input-Output Table: Compilation and Analysis. Studies in Methods - Handbook of National Accounting, Series F, No. 74. Department for Economic and Social Affairs, Statistics Division, New York. Available at: <http://unstats.un.org/unsd/publication/SeriesF/SeriesF_74E.pdf> [Accessed 13 July 2011]. 


\section{Annex 1 - Primary Data}

\begin{tabular}{|c|c|c|c|c|c|c|c|c|c|c|c|}
\hline & wny1 & wny2 & wny3 & wny4 & wny5 & wny6 & wny7 & wny8 & wny9 & wny10 & Sum \\
\hline 1989 & 0.048262 & -0.0527 & 0.012775 & 0.150968 & 0.147187 & 0.150087 & -0.00015 & 0.178946 & 0.030189 & 0.334442 & 1 \\
\hline 1990 & 0.168653 & -0.05838 & 0.009659 & 0.133226 & 0.110923 & 0.137788 & -0.02274 & 0.130723 & 0.048014 & 0.342128 & 1 \\
\hline 1991 & 0.163945 & -0.04206 & 0.004601 & 0.146278 & 0.089337 & 0.09898 & -0.01931 & 0.097833 & 0.042035 & 0.41836 & 1 \\
\hline 1992 & 0.167268 & -0.04839 & 0.027633 & 0.140971 & 0.062975 & 0.085371 & -0.00117 & 0.107102 & 0.052165 & 0.40608 & 1 \\
\hline 1993 & 0.192613 & -0.02476 & 0.017988 & 0.128219 & 0.066108 & 0.088558 & 0.019899 & 0.117318 & 0.059063 & 0.334998 & 1 \\
\hline 1994 & 0.175469 & -0.02455 & 0.010386 & 0.118841 & 0.059742 & 0.097298 & 0.033051 & 0.135045 & 0.080752 & 0.313964 & 1 \\
\hline 1995 & 0.162887 & -0.0311 & 0.022485 & 0.101425 & 0.034247 & 0.064415 & -0.00502 & 0.12864 & 0.097971 & 0.42405 & 1 \\
\hline 1996 & 0.155846 & -0.04385 & 0.02543 & 0.104314 & 0.037467 & 0.050052 & -0.03048 & 0.131919 & 0.118795 & 0.45051 & 1 \\
\hline 1997 & 0.140337 & -0.03904 & 0.032751 & 0.123863 & 0.035899 & 0.053298 & -0.02317 & 0.114477 & 0.118364 & 0.443212 & 1 \\
\hline 1998 & 0.132471 & -0.027 & 0.019152 & 0.116699 & 0.024033 & 0.036631 & -0.02006 & 0.108243 & 0.116542 & 0.493285 & 1 \\
\hline 1999 & 0.120979 & -0.02162 & 0.019357 & 0.102362 & 0.017935 & 0.02339 & -0.04732 & 0.106375 & 0.123671 & 0.554869 & 1 \\
\hline 2000 & 0.103072 & -0.02981 & 0.021493 & 0.09348 & 0.028984 & 0.033551 & -0.03166 & 0.105409 & 0.123697 & 0.551783 & 1 \\
\hline 2001 & 0.137851 & -0.02633 & 0.021078 & 0.094425 & 0.029625 & 0.041231 & -0.05821 & 0.112644 & 0.125483 & 0.522205 & 1 \\
\hline 2002 & 0.122762 & -0.0243 & 0.021464 & 0.083853 & 0.036269 & 0.053189 & -0.04913 & 0.117855 & 0.116775 & 0.521259 & 1 \\
\hline 2003 & 0.111937 & -0.02952 & 0.026023 & 0.073832 & 0.03965 & 0.045003 & -0.05781 & 0.115624 & 0.120897 & 0.554363 & 1 \\
\hline 2004 & 0.11768 & -0.02642 & 0.023421 & 0.076871 & 0.039964 & 0.046082 & -0.05545 & 0.120787 & 0.125531 & 0.531537 & 1 \\
\hline 2005 & 0.08144 & -0.03057 & 0.025577 & 0.069404 & 0.034704 & 0.053403 & -0.05565 & 0.134625 & 0.127652 & 0.559409 & 1 \\
\hline 2006 & 0.074536 & -0.02922 & 0.024819 & 0.065893 & 0.03501 & 0.056554 & -0.0554 & 0.142902 & 0.123876 & 0.561037 & 1 \\
\hline 2007 & 0.059881 & -0.02989 & 0.022166 & 0.059101 & 0.033058 & 0.058143 & -0.06542 & 0.176494 & 0.123324 & 0.563143 & 1 \\
\hline 2008 & 0.061008 & -0.03183 & 0.020379 & 0.053667 & 0.024648 & 0.057437 & -0.07251 & 0.203408 & 0.114925 & 0.568862 & 1 \\
\hline 2009 & 0.056857 & -0.03308 & 0.022693 & 0.060121 & 0.026784 & 0.060857 & -0.0621 & 0.188315 & 0.119829 & 0.559727 & 1 \\
\hline
\end{tabular}


Annex 2 - Unit Root Tests

\begin{tabular}{|c|c|c|c|c|c|c|c|c|c|c|c|c|}
\hline & ADF & & \multicolumn{2}{|c|}{ ADF } & \multicolumn{2}{|c|}{ ADF } & \multicolumn{2}{|c|}{ PP } & \multicolumn{2}{|l|}{ PP } & \multicolumn{2}{|c|}{ PP } \\
\hline Exogenous & none & & const & & constant, lir & ear trend & non & & const & & constant, li & ear trend \\
\hline Series & t-Statistic & Prob. & t-Statistic & Prob. & t-Statistic & Prob. & t-Statistic & Prob. & t-Statistic & Prob. & t-Statistic & Prob. \\
\hline wny1 & -0.49757 & 0.4877 & -1.85453 & 0.3453 & -8.82642 & 0 & -0.49757 & 0.4877 & -2.11812 & 0.2401 & -8.95694 & 0 \\
\hline$d($ wny1) & -8.78457 & 0 & -9.10973 & 0 & -8.6088 & 0 & -8.88132 & 0 & -10.2238 & 0 & -9.69526 & 0 \\
\hline$d($ wny 1,2$)$ & -7.88116 & 0 & -7.71818 & 0 & -8.05288 & 0 & -17.3099 & 0.0001 & -20.1353 & 0 & -28.2034 & 0.0001 \\
\hline wny2 & -1.44873 & 0.1328 & -3.5946 & 0.0163 & -3.00223 & 0.1569 & -1.23316 & 0.1921 & -2.6268 & 0.1043 & -2.48099 & 0.3325 \\
\hline d(wny2) & -3.50489 & 0.0016 & -3.57342 & 0.0185 & 1826 & 0.0119 & -5.28847 & 0 & -5.33599 & 0.0004 & -7.79111 & 0 \\
\hline $\mathrm{d}($ wny2,2) & -5.82122 & 0 & -5.83729 & 0.0003 & 5033 & 0.0011 & -18.6282 & 0.0001 & -23.2492 & 0 & -23.781 & 0.0001 \\
\hline wny3 & -0.54466 & 0.4682 & -3.04431 & 0.0486 & 5893 & 0.0871 & -0.23673 & 0.5883 & -3.15783 & 0.0382 & -3.65854 & 0.05 \\
\hline d(wny3) & -6.10752 & 0 & -5.98995 & 0.0001 & 2534 & 0.0007 & -8.50594 & 0 & -10.2451 & 0 & -13.0772 & 0 \\
\hline$d(w n y 3,2)$ & -5.60414 & 0 & -5.31553 & 0.0008 & -5.06679 & 0.0057 & -16.7268 & 0.0001 & -15.8331 & 0 & -15.1331 & 0.0001 \\
\hline wny4 & -2.38998 & 0.0197 & -1.14369 & 0.6769 & -3.97456 & 0.0288 & -7.15596 & 0 & -1.21447 & 0.6468 & -2.96958 & 0.164 \\
\hline $\mathrm{d}($ wny4) & -4.07833 & 0.0004 & -4.65097 & 0.002 & -4.51403 & 0.0111 & -4.07883 & 0.0004 & -6.00802 & 0.0001 & -5.74147 & 0.001 \\
\hline $\mathrm{d}($ wny4,2) & -4.61277 & 0.0002 & -4.43228 & 0.0042 & -4.20478 & 0.024 & -10.3869 & 0.0001 & -9.98937 & 0 & -13.746 & 0 \\
\hline wny5 & -1.11361 & 0.23 & -6.23659 & 0.0001 & -1.41598 & 0.8175 & -5.1666 & $\begin{array}{l}0 \\
\end{array}$ & -18.0733 & 0 & -10.0982 & 0 \\
\hline $\mathrm{d}($ wny5) & -4.57211 & 0.0001 & -4.18976 & 0.0055 & -3.13714 & 0.1295 & -3.92387 & 0.0005 & -4.23813 & 0.0043 & -5.03481 & 0.0038 \\
\hline$d(w n y 5,2)$ & -5.45953 & 0 & -5.63665 & 0.0003 & -6.53563 & 0.0003 & -7.72718 & 0 & -8.93326 & 0 & -12.4608 & 0 \\
\hline wny6 & -2.78768 & 0.0079 & -3.36236 & 0.0253 & -1.89819 & 0.618 & -2.79601 & 0.0077 & -3.9569 & 0.0073 & 91524 & 0.1786 \\
\hline $\mathrm{d}($ wny6) & -3.15639 & 0.0033 & -3.22737 & 0.0341 & -5.22045 & 0.003 & -3.11006 & 0.0037 & -3.17357 & 0.0379 & 969 & 0.0004 \\
\hline$d(w n y 6,2)$ & -5.85327 & 0 & -5.77085 & 0.0003 & -5.62966 & 0.0017 & -7.26922 & 0 & -9.19339 & 0 & -11.5825 & 0 \\
\hline wny7 & -0.2891 & 0.5689 & -1.33336 & 0.593 & -2.52211 & 0.3151 & -0.20281 & 0.6006 & -1.34804 & 0.5861 & -2.58102 & 0.2911 \\
\hline d(wny7) & -4.66468 & 0.0001 & -3.44427 & 0.0238 & -3.23003 & 116 & -4.66445 & 0.0001 & -4.61616 & 0.0019 & -4.5236 & 0.0102 \\
\hline$d(w n y 7,2)$ & -6.72343 & 0 & -6.52754 & 0 & -6.28587 & 0.0004 & -16.9189 & 0.0001 & -16.4021 & 0 & -16.396 & 0.0001 \\
\hline wny8 & -0.14912 & 0.6197 & -1.28678 & 0.6146 & -2.71697 & 0.2406 & -0.2264 & 0.592 & -1.792 & 0.3733 & -2.69394 & 0.2487 \\
\hline $\mathrm{d}$ (wny8) & -3.61069 & 0.0011 & -3.61859 & 0.0155 & -3.05806 & 0.1435 & -3.61069 & 0.0011 & -3.68561 & 0.0135 & -2.9579 & 0.1682 \\
\hline$d($ wny8,2) & -3.67769 & 0.001 & -3.58325 & 0.0213 & -2.63415 & 0.2728 & -3.60864 & 0.0012 & -3.4321 & 0.0235 & -3.75512 & 0.0446 \\
\hline wny9 & 0.670172 & 0.8519 & -2.7656 & 0.0811 & -0.9 & 0.9225 & 0.868327 & 0.8893 & -2.65938 & 0.0984 & 224 & 0.9175 \\
\hline d(wny9) & -3.21374 & 0.0029 & -3.4575 & 0.0215 & & 0.0312 & -3.26938 & 0.0025 & -3.53678 & 0.0183 & -3.95982 & 0.0296 \\
\hline $\mathrm{d}($ wny9,2) & -7.96223 & 0 & -7.65911 & 0 & -7.45452 & 0.0001 & -7.73633 & 0 & -7.44974 & 0 & -7.43856 & 0.0001 \\
\hline wny10 & 0.940482 & 0.9009 & -1.47369 & 0.5258 & -2.22116 & 0.4536 & 2.016917 & 0.9861 & -1.45735 & 0.5338 & 7269 & 0.4779 \\
\hline $\mathrm{d}($ wny10) & -5.11521 & 0 & -5.59069 & 0.0003 & -5.39855 & 0.0022 & -3.79103 & 0.0007 & -5.16063 & 0.0006 & -6.4748 & 0.0003 \\
\hline $\mathrm{d}($ wny 10,2$)$ & -6.94631 & 0 & -6.70584 & 0 & -6.4562 & 0.0004 & -8.59672 & 0 & -9.0317 & 0 & -8.64329 & 0 \\
\hline
\end{tabular}


Annex 3 - System SySw

\begin{tabular}{|c|c|c|c|c|c|c|c|c|c|}
\hline \multicolumn{5}{|c|}{ OLS } & \multicolumn{5}{|c|}{ WLS } \\
\hline & Coefficient & Std.Error & $\mathrm{t}$-Statistic & Prob. & & Coefficient & Std.Error & t-Statistic & Prob. \\
\hline$c(1)$ & 0.347946 & 0.049816 & 6.984678 & 0 & $c(1)$ & 0.347946 & 0.045928 & 7.575947 & 0 \\
\hline$c(2)$ & -0.420552 & 0.092465 & -4.548209 & 0 & $c(2)$ & -0.420552 & 0.085249 & -4.933226 & 0 \\
\hline$c(3)$ & -0.331256 & 0.051712 & -6.405835 & 0 & $\mathrm{c}(3)$ & -0.331256 & 0.047676 & -6.948103 & 0 \\
\hline$c(4)$ & -0.015687 & 0.005449 & -2.879071 & 0.0045 & $c(4)$ & -0.015687 & 0.005023 & -3.122791 & 0.0021 \\
\hline$c(5)$ & -0.776813 & 0.221071 & -3.513867 & 0.0006 & $c(5)$ & -0.776813 & 0.203817 & -3.811324 & 0.0002 \\
\hline$c(6)$ & -0.141417 & 0.068127 & -2.075803 & 0.0395 & $c(6)$ & -0.141417 & 0.06281 & -2.251525 & 0.0257 \\
\hline $\mathrm{c}(7)$ & 0.033237 & 0.007182 & 4.627793 & 0 & $\mathrm{c}(7)$ & 0.033237 & 0.006621 & 5.019546 & 0 \\
\hline$c(8)$ & -1.146095 & 0.231273 & -4.955593 & 0 & $c(8)$ & -1.146095 & 0.213223 & -5.375096 & 0 \\
\hline $\mathrm{c}(9)$ & -0.140158 & 0.046434 & -3.018427 & 0.0029 & $c(9)$ & -0.140158 & 0.04281 & -3.273944 & 0.0013 \\
\hline$c(10)$ & -0.014292 & 0.006137 & -2.328897 & 0.0211 & $c(10)$ & -0.014292 & 0.005489 & -2.603786 & 0.0101 \\
\hline$c(11)$ & -0.39046 & 0.076313 & -5.11655 & 0 & $c(11)$ & -0.39046 & 0.068257 & -5.720476 & 0 \\
\hline$c(12)$ & 0.155279 & 0.043831 & 3.542659 & 0.0005 & $c(12)$ & 0.155279 & 0.039204 & 3.960813 & 0.0001 \\
\hline$c(13)$ & -0.897608 & 0.181288 & -4.951277 & 0 & $c(13)$ & -0.897608 & 0.162149 & -5.535696 & 0 \\
\hline$c(14)$ & 0.009537 & 0.002966 & 3.215898 & 0.0016 & $c(14)$ & 0.009537 & 0.002814 & 3.389854 & 0.0009 \\
\hline$c(15)$ & -0.315006 & 0.050509 & -6.236592 & 0 & $c(15)$ & -0.315006 & 0.047917 & -6.573945 & 0 \\
\hline$c(16)$ & 0.011526 & 0.003254 & 3.541524 & 0.0005 & $c(16)$ & 0.011526 & 0.003 & 3.841322 & 0.0002 \\
\hline $\mathrm{c}(17)$ & -0.201363 & 0.04482 & -4.492747 & 0 & $c(17)$ & -0.201363 & 0.041322 & -4.873069 & 0 \\
\hline$c(18)$ & -0.230093 & 0.03684 & -6.245803 & 0 & $c(18)$ & -0.230093 & 0.033964 & -6.774525 & 0 \\
\hline$c(19)$ & -0.056252 & 0.015986 & -3.518716 & 0.0006 & $c(19)$ & -0.056252 & 0.013723 & -4.09918 & 0.0001 \\
\hline$c(20)$ & -0.416294 & 0.129967 & -3.203069 & 0.0016 & $c(20)$ & -0.416294 & 0.111563 & -3.731463 & 0.0003 \\
\hline$c(21)$ & 0.44973 & 0.131906 & 3.409474 & 0.0008 & $c(21)$ & 0.44973 & 0.113227 & 3.971917 & 0.0001 \\
\hline $\mathrm{c}(22)$ & 0.520374 & 0.168229 & 3.093243 & 0.0023 & $c(22)$ & 0.520374 & 0.144407 & 3.603519 & 0.0004 \\
\hline$c(23)$ & -0.219588 & 0.069397 & -3.164221 & 0.0019 & $c(23)$ & -0.219588 & 0.05957 & -3.686206 & 0.0003 \\
\hline$c(24)$ & 0.089253 & 0.024743 & 3.607261 & 0.0004 & $c(24)$ & 0.089253 & 0.022811 & 3.912624 & 0.0001 \\
\hline$c(25)$ & -0.362136 & 0.131883 & -2.74588 & 0.0067 & $c(25)$ & -0.362136 & 0.12159 & -2.978325 & 0.0033 \\
\hline$c(26)$ & -0.411774 & 0.121955 & -3.376452 & 0.0009 & $c(26)$ & -0.411774 & 0.112437 & -3.662276 & 0.0003 \\
\hline$c(27)$ & 0.052974 & 0.011017 & 4.808415 & 0 & $c(27)$ & 0.052974 & 0.010157 & 5.215458 & 0 \\
\hline$c(28)$ & -0.276179 & 0.057352 & -4.815548 & 0 & $c(28)$ & -0.276179 & 0.052876 & -5.223196 & 0 \\
\hline$c(29)$ & 0.626097 & 0.186798 & 3.351736 & 0.001 & $c(29)$ & 0.626097 & 0.172219 & 3.635468 & 0.0004 \\
\hline$c(30)$ & -0.110826 & 0.039257 & -2.823086 & 0.0053 & $c(30)$ & -0.110826 & 0.032472 & -3.412945 & 0.0008 \\
\hline $\mathrm{c}(31)$ & 0.223586 & 0.076059 & 2.93964 & 0.0038 & $c(31)$ & 0.223586 & 0.062914 & 3.553851 & 0.0005 \\
\hline
\end{tabular}




\begin{tabular}{|c|c|c|c|c|c|c|c|c|c|}
\hline \multicolumn{5}{|c|}{ OLS } & \multicolumn{5}{|c|}{ WLS } \\
\hline & Coefficient & Std.Error & t-Statistic & Prob. & & Coefficient & Std.Error & $\mathrm{t}$-Statistic & Prob. \\
\hline$c(32)$ & -1.311648 & 0.324631 & -4.040423 & 0.0001 & $c(32)$ & -1.311648 & 0.268525 & -4.884633 & 0 \\
\hline$c(33)$ & -1.984356 & 0.44276 & -4.481788 & 0 & $c(33)$ & -1.984356 & 0.366238 & -5.418217 & 0 \\
\hline$c(34)$ & -1.093953 & 0.296356 & -3.691343 & 0.0003 & $c(34)$ & -1.093953 & 0.245137 & -4.462617 & 0 \\
\hline$c(35)$ & 1.836526 & 0.612198 & 2.999891 & 0.0031 & $c(35)$ & 1.836526 & 0.506392 & 3.626692 & 0.0004 \\
\hline \multicolumn{5}{|c|}{ SUR } & \multicolumn{5}{|c|}{ 2SLS } \\
\hline & Coefficient & Std.Error & t-Statistic & Prob. & & Coefficient & Std.Error & t-Statistic & Prob. \\
\hline$c(1)$ & 0.355425 & 0.038901 & 9.136695 & 0 & $c(1)$ & 0.321759 & 0.056781 & 5.666681 & 0 \\
\hline$c(2)$ & -0.460663 & 0.068483 & -6.726651 & 0 & $c(2)$ & -0.304126 & 0.13946 & -2.180742 & 0.0307 \\
\hline$c(3)$ & -0.333842 & 0.04213 & -7.924038 & 0 & $c(3)$ & -0.318185 & 0.055234 & -5.760646 & 0 \\
\hline$c(4)$ & -0.017512 & 0.004511 & -3.88223 & 0.0002 & $c(4)$ & -0.019364 & 0.008316 & -2.328488 & 0.0212 \\
\hline$c(5)$ & -0.855068 & 0.155632 & -5.494149 & 0 & $c(5)$ & -1.03625 & 0.414401 & -2.500596 & 0.0134 \\
\hline$c(6)$ & -0.153611 & 0.048905 & -3.141018 & 0.002 & $c(6)$ & -0.217042 & 0.113599 & -1.910598 & 0.0579 \\
\hline$c(7)$ & 0.03429 & 0.005205 & 6.588489 & 0 & $c(7)$ & 0.042299 & 0.009976 & 4.239927 & 0 \\
\hline$c(8)$ & -1.157882 & 0.160009 & -7.236336 & 0 & $c(8)$ & -1.415679 & 0.293991 & -4.815382 & 0 \\
\hline$c(9)$ & -0.152763 & 0.038156 & -4.003652 & 0.0001 & $\mathrm{c}(9)$ & -0.195047 & 0.074334 & -2.623925 & 0.0095 \\
\hline$c(10)$ & -0.015306 & 0.004849 & -3.156866 & 0.0019 & $c(10)$ & -0.014634 & 0.008475 & -1.726762 & 0.0862 \\
\hline$c(11)$ & -0.406511 & 0.051271 & -7.928749 & 0 & $c(11)$ & -0.458196 & 0.179313 & -2.555282 & 0.0116 \\
\hline$c(12)$ & 0.188159 & 0.02799 & 6.722277 & 0 & $c(12)$ & 0.210405 & 0.11555 & 1.820895 & 0.0705 \\
\hline$c(13)$ & -0.855844 & 0.135204 & -6.329996 & 0 & $c(13)$ & -0.895211 & 0.354586 & -2.524668 & 0.0126 \\
\hline$c(14)$ & 0.009895 & 0.002771 & 3.571364 & 0.0005 & $c(14)$ & 0.00904 & 0.003811 & 2.372293 & 0.0189 \\
\hline$c(15)$ & -0.323059 & 0.046704 & -6.917199 & 0 & $c(15)$ & -0.30444 & 0.077146 & -3.946277 & 0.0001 \\
\hline$c(16)$ & 0.010985 & 0.002925 & 3.755611 & 0.0002 & $c(16)$ & 0.016649 & 0.004372 & 3.808547 & 0.0002 \\
\hline$c(17)$ & -0.18959 & 0.039602 & -4.78741 & 0 & $c(17)$ & -0.278596 & 0.069738 & -3.994873 & 0.0001 \\
\hline$c(18)$ & -0.251489 & 0.030759 & -8.176094 & 0 & $c(18)$ & -0.296052 & 0.104044 & -2.845464 & 0.005 \\
\hline$c(19)$ & -0.055918 & 0.011672 & -4.790862 & 0 & $c(19)$ & -0.062866 & 0.02877 & -2.185108 & 0.0304 \\
\hline$c(20)$ & -0.390748 & 0.092767 & -4.21214 & 0 & $c(20)$ & -0.459766 & 0.23433 & -1.962041 & 0.0515 \\
\hline$c(21)$ & 0.450151 & 0.097443 & 4.619622 & 0 & $c(21)$ & 0.505896 & 0.228943 & 2.209704 & 0.0286 \\
\hline$c(22)$ & 0.496568 & 0.125003 & 3.972431 & 0.0001 & $c(22)$ & 0.560651 & 0.213097 & 2.630969 & 0.0094 \\
\hline$c(23)$ & -0.210551 & 0.050693 & -4.153487 & 0.0001 & $c(23)$ & -0.235236 & 0.074473 & -3.158688 & 0.0019 \\
\hline$c(24)$ & 0.086636 & 0.020614 & 4.202776 & 0 & $c(24)$ & 0.105522 & 0.038867 & 2.714966 & 0.0074 \\
\hline$c(25)$ & -0.359571 & 0.105044 & -3.423038 & 0.0008 & $c(25)$ & -0.565262 & 0.236625 & -2.388852 & 0.0181 \\
\hline
\end{tabular}




\begin{tabular}{|c|c|c|c|c|c|c|c|c|c|}
\hline \multicolumn{5}{|c|}{ SUR } & \multicolumn{5}{|c|}{ 2SLS } \\
\hline & Coefficient & Std.Error & t-Statistic & Prob. & & Coefficient & Std.Error & t-Statistic & Prob. \\
\hline$c(26)$ & -0.390103 & 0.106642 & -3.658052 & 0.0003 & $c(26)$ & -0.313641 & 0.1542 & -2.033993 & 0.0436 \\
\hline$c(27)$ & 0.05878 & 0.008357 & 7.033287 & 0 & $c(27)$ & 0.064503 & 0.016696 & 3.863421 & 0.0002 \\
\hline$c(28)$ & -0.306302 & 0.045404 & -6.746212 & 0 & $c(28)$ & -0.313138 & 0.078413 & -3.993439 & 0.0001 \\
\hline$c(29)$ & 0.708455 & 0.142846 & 4.959583 & 0 & $\mathrm{c}(29)$ & 0.873124 & 0.298082 & 2.929142 & 0.0039 \\
\hline $\mathrm{c}(30)$ & -0.085789 & 0.02735 & -3.136727 & 0.002 & $\mathrm{c}(30)$ & -0.116095 & 0.044712 & -2.596484 & 0.0103 \\
\hline $\mathrm{c}(31)$ & 0.175736 & 0.053433 & 3.28893 & 0.0012 & $c(31)$ & 0.234122 & 0.086419 & 2.709163 & 0.0075 \\
\hline$c(32)$ & -1.201476 & 0.214677 & -5.596677 & 0 & $c(32)$ & -1.042519 & 0.371276 & -2.807934 & 0.0056 \\
\hline $\mathrm{c}(33)$ & -1.970749 & 0.296757 & -6.640948 & 0 & $c(33)$ & -2.036676 & 0.465497 & -4.375271 & 0 \\
\hline$c(34)$ & -0.773446 & 0.201248 & -3.843257 & 0.0002 & $\mathrm{c}(34)$ & -1.051822 & 0.307666 & -3.418716 & 0.0008 \\
\hline$c(35)$ & 1.363127 & 0.384794 & 3.542485 & 0.0005 & $c(35)$ & 1.815241 & 0.713547 & 2.54397 & 0.0119 \\
\hline
\end{tabular}

\begin{tabular}{|c|c|c|c|c|c|c|c|c|c|}
\hline \multicolumn{5}{|c|}{ W2SLS } & \multicolumn{5}{|c|}{ 3SLS } \\
\hline & Coefficient & Std.Error & t-Statistic & Prob. & & Coefficient & Std.Error & t-Statistic & Prob. \\
\hline$c(1)$ & 0.321759 & 0.052349 & 6.146378 & 0 & $c(1)$ & 0.321759 & 0.052349 & 6.146378 & 0 \\
\hline$c(2)$ & -0.304126 & 0.128576 & -2.365347 & 0.0192 & $c(2)$ & -0.304126 & 0.128576 & -2.365347 & 0.0192 \\
\hline$c(3)$ & -0.318185 & 0.050923 & -6.248298 & 0 & $c(3)$ & -0.318185 & 0.050923 & -6.248298 & 0 \\
\hline$c(4)$ & -0.019364 & 0.007667 & -2.5256 & 0.0125 & $c(4)$ & -0.019364 & 0.007667 & -2.5256 & 0.0125 \\
\hline$c(5)$ & -1.03625 & 0.382059 & -2.712277 & 0.0074 & $c(5)$ & -1.03625 & 0.382059 & -2.712277 & 0.0074 \\
\hline$c(6)$ & -0.217042 & 0.104733 & -2.072334 & 0.0399 & $c(6)$ & -0.217042 & 0.104733 & -2.072334 & 0.0399 \\
\hline $\mathrm{c}(7)$ & 0.042299 & 0.009155 & 4.620353 & 0 & $c(7)$ & 0.042299 & 0.009155 & 4.620353 & 0 \\
\hline$c(8)$ & -1.415679 & 0.269785 & -5.247441 & 0 & $c(8)$ & -1.415679 & 0.269785 & -5.247441 & 0 \\
\hline$c(9)$ & -0.195047 & 0.068214 & -2.859356 & 0.0048 & $c(9)$ & -0.195047 & 0.068214 & -2.859356 & 0.0048 \\
\hline$c(10)$ & -0.014634 & 0.00753 & -1.943407 & 0.0537 & $c(10)$ & -0.014634 & 0.00753 & -1.943407 & 0.0537 \\
\hline $\mathrm{c}(11)$ & -0.458196 & 0.159324 & -2.875875 & 0.0046 & $c(11)$ & -0.458196 & 0.159324 & -2.875875 & 0.0046 \\
\hline$c(12)$ & 0.210405 & 0.102669 & 2.04935 & 0.0421 & $c(12)$ & 0.210405 & 0.102669 & 2.04935 & 0.0421 \\
\hline$c(13)$ & -0.895211 & 0.315058 & -2.841421 & 0.0051 & $c(13)$ & -0.895211 & 0.315058 & -2.841421 & 0.0051 \\
\hline$c(14)$ & 0.00904 & 0.003605 & 2.507961 & 0.0132 & $c(14)$ & 0.00904 & 0.003605 & 2.507961 & 0.0132 \\
\hline$c(15)$ & -0.30444 & 0.072973 & -4.171957 & 0 & $c(15)$ & -0.30444 & 0.072973 & -4.171957 & 0 \\
\hline
\end{tabular}




\begin{tabular}{|c|c|c|c|c|c|c|c|c|c|}
\hline \multicolumn{5}{|c|}{ W2SLS } & \multicolumn{5}{|c|}{$3 S L S$} \\
\hline & Coefficient & Std.Error & t-Statistic & Prob. & & Coefficient & Std.Error & t-Statistic & Prob. \\
\hline$c(16)$ & 0.016649 & 0.004012 & 4.150268 & 0.0001 & $c(16)$ & 0.016649 & 0.004012 & 4.150268 & 0.0001 \\
\hline$c(17)$ & -0.278596 & 0.063996 & -4.353312 & 0 & $c(17)$ & -0.278596 & 0.063996 & -4.353312 & 0 \\
\hline$c(18)$ & -0.296052 & 0.095477 & -3.100772 & 0.0023 & $c(18)$ & -0.296052 & 0.095477 & -3.100772 & 0.0023 \\
\hline$c(19)$ & -0.062866 & 0.024696 & -2.545574 & 0.0119 & $c(19)$ & -0.062866 & 0.024696 & -2.545574 & 0.0119 \\
\hline$c(20)$ & -0.459766 & 0.201148 & -2.285709 & 0.0236 & $c(20)$ & -0.459766 & 0.201148 & -2.285709 & 0.0236 \\
\hline$c(21)$ & 0.505896 & 0.196523 & 2.574228 & 0.011 & $c(21)$ & 0.505896 & 0.196523 & 2.574228 & 0.011 \\
\hline $\mathrm{c}(22)$ & 0.560651 & 0.182921 & 3.064986 & 0.0026 & $\mathrm{c}(22)$ & 0.560651 & 0.182921 & 3.064986 & 0.0026 \\
\hline$c(23)$ & -0.235236 & 0.063927 & -3.67976 & 0.0003 & $c(23)$ & -0.235236 & 0.063927 & -3.67976 & 0.0003 \\
\hline$c(24)$ & 0.105522 & 0.035834 & 2.944794 & 0.0037 & $c(24)$ & 0.105522 & 0.035834 & 2.944794 & 0.0037 \\
\hline$c(25)$ & -0.565262 & 0.218158 & -2.591073 & 0.0105 & $c(25)$ & -0.565262 & 0.218158 & -2.591073 & 0.0105 \\
\hline$c(26)$ & -0.313641 & 0.142165 & -2.206175 & 0.0288 & $c(26)$ & -0.313641 & 0.142165 & -2.206175 & 0.0288 \\
\hline$c(27)$ & 0.064503 & 0.015321 & 4.210065 & 0 & $c(27)$ & 0.064503 & 0.015321 & 4.210065 & 0 \\
\hline$c(28)$ & -0.313138 & 0.071957 & -4.35175 & 0 & $c(28)$ & -0.313138 & 0.071957 & -4.35175 & 0 \\
\hline$c(29)$ & 0.873124 & 0.273539 & 3.191958 & 0.0017 & $c(29)$ & 0.873124 & 0.273539 & 3.191958 & 0.0017 \\
\hline $\mathrm{c}(30)$ & -0.116095 & 0.036985 & -3.138997 & 0.002 & $\mathrm{c}(30)$ & -0.116095 & 0.036985 & -3.138997 & 0.002 \\
\hline$c(31)$ & 0.234122 & 0.071483 & 3.275218 & 0.0013 & $\mathrm{c}(31)$ & 0.234122 & 0.071483 & 3.275218 & 0.0013 \\
\hline $\mathrm{c}(32)$ & -1.042519 & 0.307109 & -3.394626 & 0.0009 & $c(32)$ & -1.042519 & 0.307109 & -3.394626 & 0.0009 \\
\hline$c(33)$ & -2.036676 & 0.385045 & -5.289444 & 0 & $\mathrm{c}(33)$ & -2.036676 & 0.385045 & -5.289444 & 0 \\
\hline$c(34)$ & -1.051822 & 0.254492 & -4.133027 & 0.0001 & $c(34)$ & -1.051822 & 0.254492 & -4.133027 & 0.0001 \\
\hline$c(35)$ & 1.815241 & 0.590225 & 3.075509 & 0.0025 & $c(35)$ & 1.815241 & 0.590225 & 3.075509 & 0.0025 \\
\hline
\end{tabular}




\section{Annex 4 - BDS Test}

\begin{tabular}{|c|c|c|c|c|c|c|c|}
\hline \multirow{2}{*}{ Series } & \multirow[b]{2}{*}{ Dimension } & \multicolumn{2}{|c|}{ Fraction of pairs } & \multicolumn{2}{|c|}{ Standard deviation } & \multicolumn{2}{|c|}{ Fraction of range } \\
\hline & & Normal prob. & Bootstrap prob. & Normal Prob. & Bootstrap Prob. & Normal Prob. & Bootstrap Prob. \\
\hline \multirow[t]{5}{*}{ reswny1 } & 2 & 0.4509 & 0.806 & 0.9224 & 0.756 & 0.3806 & 0.954 \\
\hline & 3 & 0.7819 & 0.676 & 0.1026 & 0.148 & 0 & 0.425 \\
\hline & 4 & 0.8107 & 0.824 & 0.1403 & 0.168 & 0 & 0.5734 \\
\hline & 5 & 0.7163 & 0.892 & 0.1824 & 0.21 & 0 & 0.4698 \\
\hline & 6 & 0.3884 & 0.956 & 0.3184 & 0.218 & 0.0004 & 0.6426 \\
\hline \multirow[t]{5}{*}{ reswny2 } & 2 & 0.9251 & 0.726 & 0.8717 & 0.8816 & 0.1769 & 0.4322 \\
\hline & 3 & 0.9028 & 0.698 & 0.0246 & 0.3058 & 0.1661 & 0.5318 \\
\hline & 4 & 0.4821 & 0.436 & 0.3668 & 0.8308 & 0.8811 & 0.8068 \\
\hline & 5 & 0.2433 & 0.278 & 0.4682 & 0.959 & 0.6261 & 0.5406 \\
\hline & 6 & 0.2362 & 0.234 & 0.7458 & 0.644 & 0.4891 & 0.4798 \\
\hline \multirow[t]{5}{*}{ reswny3 } & 2 & 0.2121 & 0.3532 & 0.0339 & 0.1676 & 0.2695 & 0.7798 \\
\hline & 3 & 0.0319 & 0.1414 & 0.0655 & 0.2088 & 0.1325 & 0.8038 \\
\hline & 4 & 0.0074 & 0.076 & 0.0448 & 0.1878 & 0.2937 & 0.6636 \\
\hline & 5 & 0.0114 & 0.0836 & 0.0132 & 0.1506 & 0.05 & 0.5392 \\
\hline & 6 & 0.0065 & 0.066 & 0.0064 & 0.1186 & 0.0026 & 0.4254 \\
\hline \multirow[t]{5}{*}{ reswny4 } & 2 & 0.287 & 0.612 & 0.3238 & 0.8546 & 0.4561 & 0.9518 \\
\hline & 3 & 0.2893 & 0.6552 & 0.0063 & 0.3806 & 0.2189 & 0.9958 \\
\hline & 4 & 0.0786 & 0.4136 & 0.0068 & 0.4052 & 0.0681 & 1 \\
\hline & 5 & 0.7163 & 0.9144 & 0.2637 & 0.9814 & 0.0006 & 0.703 \\
\hline & 6 & 0.9548 & 0.6608 & 0.459 & 0.822 & 0 & 0.5588 \\
\hline \multirow[t]{5}{*}{ reswny5 } & 2 & 0.9014 & 0.7896 & 0.2118 & 0.4314 & 0.2479 & 0.863 \\
\hline & 3 & 0.2914 & 0.7592 & 0.0415 & 0.1662 & 0.1257 & 0.8872 \\
\hline & 4 & 0.8544 & 0.7008 & 0.0668 & 0.2204 & 0.8084 & 0.813 \\
\hline & 5 & 0.1853 & 0.3396 & 0.4533 & 0.6722 & 0.0008 & 0.4694 \\
\hline & 6 & 0.0695 & 0.2264 & 0.5072 & 0.669 & 0 & 0.3308 \\
\hline \multirow[t]{5}{*}{ reswny6 } & 2 & 0.009 & 0.178 & 0.6802 & 0.7383 & 0.0072 & 0.299 \\
\hline & 3 & 0.0176 & 0.178 & 0.0002 & 0.3049 & 0.0159 & 0.3164 \\
\hline & 4 & 0.1587 & 0.348 & 0.0289 & 0.8648 & 0.0111 & 0.2884 \\
\hline & 5 & 0.9005 & 0.734 & 0.0001 & 0.5097 & 0.0059 & 0.2432 \\
\hline & 6 & 0.0588 & 0.598 & 0.0001 & 0.4663 & 0.8711 & 0.7288 \\
\hline
\end{tabular}




\begin{tabular}{|c|c|c|c|c|c|c|c|}
\hline \multirow{2}{*}{ Series } & \multicolumn{2}{|c|}{ Fraction of pairs } & \multicolumn{2}{c|}{ Standard deviation } & \multicolumn{2}{c|}{ Fraction of range } \\
\cline { 2 - 8 } & Dimension & Normal prob. & Bootstrap prob. & Normal Prob. & Bootstrap Prob. & Normal Prob. & Bootstrap Prob. \\
\hline reswny7 & 2 & 0.9371 & 0.812 & 0.9516 & 0.853 & 0.4017 & 0.7998 \\
\hline & 3 & 0.4296 & 0.482 & 0.9793 & 0.7796 & 0.7405 & 0.9002 \\
\hline & 4 & 0.4075 & 0.468 & 0.2934 & 0.6954 & 0.9035 & 0.726 \\
\hline & 5 & 0.8205 & 0.634 & 0.2829 & 0.633 & 0.1987 & 0.8662 \\
\hline & 6 & 0.9807 & 0.728 & 0.4201 & 0.709 & 0.6341 & 0.8816 \\
\hline reswny8 & 2 & 0.0234 & 0.186 & 0.0543 & 0.252 & 0.707 & 0.7938 \\
\hline & 3 & 0.7986 & 0.6972 & 0.001 & 0.1018 & 0.0366 & 0.5974 \\
\hline & 4 & 0.0654 & 0.4482 & 0.0001 & 0.0794 & 0 & 0.2214 \\
\hline & 5 & 0.9411 & 0.7688 & 0 & 0.0392 & 0.0264 & 0.6182 \\
\hline & 6 & 0.1194 & 0.2268 & 0 & 0.042 & 0.9257 & 0.8136 \\
\hline reswny9 & 2 & 0.3908 & 0.7458 & 0.8916 & 0.7846 & 0.551 & 0.9904 \\
\hline & 3 & 0.0828 & 0.4018 & 0.1517 & 0.5666 & 0.0077 & 0.7732 \\
\hline & 4 & 0.2073 & 0.6124 & 0.4613 & 0.9318 & 0.6748 & 0.8074 \\
\hline & 5 & 0.2543 & 0.6926 & 0.8752 & 0.5644 & 0.0045 & 0.591 \\
\hline & 6 & 0.1725 & 0.5836 & 0.5844 & 0.9856 & 0 & 0.491 \\
\hline & 2 & 0.1613 & 0.5 & 0.0476 & 0.1074 & 0.397 & 0.77 \\
\hline & 3 & 0.1003 & 0.42 & 0.1292 & 0.167 & 0.0906 & 0.5964 \\
\hline & 4 & 0.2338 & 0.54 & 0.3645 & 0.2732 & 0.0262 & 0.5116 \\
\hline & 5 & 0.2738 & 0.74 & 0.6691 & 0.948 & 0.0153 & 0.492 \\
\hline
\end{tabular}


Annex 5 - Weights in Fisher Linear Moving Average

\begin{tabular}{|l|c|c|c|c|c|c|c|c|c|c|c|}
\hline \multicolumn{1}{|c|}{$\mathrm{t}$} & \multicolumn{9}{|c|}{ Number of terms } \\
\hline & 2 & 3 & 4 & 5 & 6 & 7 & 8 & 9 & 10 & 11 & 12 \\
\hline $\mathrm{t}$ & 0.66667 & 0.5 & 0.4 & 0.33333 & 0.28571 & 0.25000 & 0.22222 & 0.20000 & 0.18182 & 0.16667 & 0.15385 \\
\hline $\mathrm{t}-1$ & 0.33333 & 0.33333 & 0.3 & 0.26667 & 0.23810 & 0.21429 & 0.19444 & 0.17778 & 0.16364 & 0.15152 & 0.14103 \\
\hline $\mathrm{t}-2$ & & 0.16667 & 0.2 & 0.20000 & 0.19048 & 0.17857 & 0.16667 & 0.15556 & 0.14545 & 0.13636 & 0.12821 \\
\hline $\mathrm{t}-3$ & & & 0.1 & 0.13333 & 0.14286 & 0.14286 & 0.13889 & 0.13333 & 0.12727 & 0.12121 & 0.11538 \\
\hline $\mathrm{t}-4$ & & & & 0.06667 & 0.09524 & 0.10714 & 0.11111 & 0.11111 & 0.10909 & 0.10606 & 0.10256 \\
\hline $\mathrm{t}-5$ & & & & & 0.04762 & 0.07143 & 0.08333 & 0.08889 & 0.09091 & 0.09091 & 0.08974 \\
\hline $\mathrm{t}-6$ & & & & & & 0.03571 & 0.05556 & 0.06667 & 0.07273 & 0.07576 & 0.07692 \\
\hline $\mathrm{t}-7$ & & & & & & & 0.02778 & 0.04444 & 0.05455 & 0.06061 & 0.06410 \\
\hline $\mathrm{t}-8$ & & & & & & & & 0.02222 & 0.03636 & 0.04545 & 0.05128 \\
\hline $\mathrm{t}-9$ & & & & & & & & & 0.01818 & 0.03030 & 0.03846 \\
\hline $\mathrm{t}-10$ & & & & & & & & & & 0.01515 & 0.02564 \\
\hline $\mathrm{t}-11$ & & & & & & & & & & & 0.01282 \\
\hline Sum & 1.00000 & 1.00000 & 1.00000 & 1.00000 & 1.00000 & 1.00000 & 1.00000 & 1.00000 & 1.00000 & 1.00000 & 1.00000 \\
\hline
\end{tabular}

From Jula, D. and N-M Jula, p. 50-54 for 4, 5, and 12 terms; the rest of weights have been completed by D. Jula in 2013. 
Annex $6-\mathrm{AlC}_{\mathrm{k}}, \tau_{\mathrm{k}}$, and $\mathrm{CV}_{\mathrm{k}}$ Parameters

\begin{tabular}{|c|c|c|c|c|c|c|c|c|c|c|c|c|}
\hline & $\begin{array}{l}\text { Number } \\
\text { of terms }\end{array}$ & 2 & 3 & 4 & 5 & 6 & 7 & 8 & 9 & 10 & 11 & 12 \\
\hline \multirow[t]{3}{*}{ wny1 } & $\mathrm{AIC}$ & 0.00015 & 0.00013 & 0.00023 & 0.00043 & 0.00061 & 0.00098 & 0.00158 & 0.00251 & 0.00396 & 0.00652 & 0.0111 \\
\hline & $\mathrm{T}$ & 6 & 8 & 9 & 11 & 13 & 14 & 16 & 17 & 19 & 20 & 22 \\
\hline & $\mathrm{CV}$ & 0.0014 & 0.00436 & 0.01037 & 0.01445 & 0.01607 & 0.01648 & 0.0159 & 0.0159 & 0.01584 & 0.01622 & 0.01496 \\
\hline \multirow[t]{3}{*}{ wny2 } & $\mathrm{AIC}$ & 1.08E-05 & 2.7E-05 & 4.5E-05 & 7E-05 & 5.7E-05 & 4.9E-05 & $6.1 \mathrm{E}-05$ & 7.7E-05 & 0.00013 & 0.00017 & 0.00012 \\
\hline & $T$ & 6 & 6 & 7 & 9 & 10 & 11 & 12 & 13 & 14 & 13 & 14 \\
\hline & $\mathrm{CV}$ & 0.00159 & 0.25019 & 0.22244 & 0.18203 & 0.23107 & 0.21461 & 0.25034 & 0.23555 & 0.26332 & 0.35004 & 0.36366 \\
\hline \multirow[t]{3}{*}{ wny3 } & $\mathrm{AIC}$ & 8.73E-06 & 2E-05 & 3E-05 & $2.2 \mathrm{E}-05$ & $3.1 \mathrm{E}-05$ & $4.2 \mathrm{E}-05$ & 5.3E-05 & $6 E-05$ & 1.8E-05 & $2.3 \mathrm{E}-05$ & 3.9E-05 \\
\hline & $T$ & 6 & 7 & 9 & 9 & 10 & 11 & 12 & 13 & 14 & 13 & 14 \\
\hline & $\mathrm{CV}$ & 0.00151 & 0.12495 & 0.00319 & 0.18165 & 0.2306 & 0.2142 & 0.24997 & 0.23531 & 0.2632 & 0.35014 & 0.36391 \\
\hline \multirow[t]{3}{*}{ wny4 } & $\mathrm{AIC}$ & $1.65 \mathrm{E}-05$ & 4.6E-05 & $9.2 \mathrm{E}-05$ & 0.00016 & 0.00026 & 0.00039 & 0.00049 & 0.00075 & 0.00134 & 0.0025 & 0.00465 \\
\hline & $\mathrm{T}$ & 6 & 7 & 9 & 11 & 12 & 14 & 15 & 17 & 18 & 20 & 21 \\
\hline & $\mathrm{CV}$ & 0.0015 & 0.12495 & 0.00477 & 0.0064 & 0.07708 & 0.00969 & 0.06317 & 0.01245 & 0.0539 & 0.01395 & 0.04713 \\
\hline \multirow[t]{3}{*}{ wny5 } & $\mathrm{AIC}$ & $2.74 \mathrm{E}-05$ & 7.3E-05 & 0.00013 & 0.00014 & 0.00023 & 0.00038 & 0.00038 & 0.00049 & 0.00071 & 0.00077 & 0.00049 \\
\hline & $T$ & 6 & 9 & 9 & 11 & 13 & 12 & 13 & 14 & 12 & 14 & 17 \\
\hline & $\mathrm{CV}$ & 0.0018 & 0.12494 & 0.00785 & 0.00771 & 0.00613 & 0.14266 & 0.18734 & 0.17641 & 0.36833 & 0.29975 & 0.22708 \\
\hline \multirow[t]{3}{*}{ wny6 } & $\mathrm{AIC}$ & $3.1 \mathrm{E}-05$ & 0.00011 & 0.00015 & 0.00021 & 0.00034 & 0.0006 & 0.00082 & 0.00101 & 0.0015 & 0.00184 & 0.00142 \\
\hline & $T$ & 6 & 6 & 7 & 9 & 10 & 11 & 15 & 15 & 15 & 17 & 16 \\
\hline & CV & 0.00119 & 0.25011 & 0.22245 & 0.1821 & 0.23123 & 0.2149 & 0.0612 & 0.11445 & 0.20418 & 0.14592 & 0.26453 \\
\hline \multirow[t]{3}{*}{ wny7 } & $\mathrm{AIC}$ & 4.3E-05 & 0.00011 & 0.00021 & 0.00033 & 0.00043 & 0.00052 & 0.00079 & 0.001 & 0.00159 & 0.0028 & 0.00397 \\
\hline & $\mathrm{T}$ & 6 & 7 & 9 & 10 & 12 & 11 & 15 & 17 & 18 & 20 & 22 \\
\hline & $\mathrm{CV}$ & 0.00237 & 0.12507 & 0.00388 & 0.09115 & 0.0772 & 0.21485 & 0.06314 & 0.01058 & 0.05458 & 0.01791 & 0.01878 \\
\hline \multirow[t]{3}{*}{ wny8 } & $\mathrm{AIC}$ & 5.1E-05 & 0.00014 & 0.0002 & 0.00035 & 0.00058 & 0.00089 & 0.0014 & 0.00222 & 0.00361 & 0.00604 & 0.01073 \\
\hline & $\mathrm{T}$ & 4 & 7 & 9 & 11 & 13 & 14 & 16 & 17 & 19 & 17 & 18 \\
\hline & $\mathrm{CV}$ & 0.33331 & 0.12524 & 0.00797 & 0.0096 & 0.01045 & 0.01111 & 0.01097 & 0.01066 & 0.0098 & 0.14659 & 0.17774 \\
\hline \multirow[t]{3}{*}{ wny9 } & $\mathrm{AIC}$ & $1.5 \mathrm{E}-05$ & 4.7E-05 & 0.00012 & 0.00022 & 0.0004 & 0.00058 & 0.00076 & 0.00072 & 0.00079 & 0.00107 & 0.00129 \\
\hline & $\mathrm{T}$ & 4 & 6 & 7 & 8 & 9 & 9 & 10 & 11 & 12 & 14 & 16 \\
\hline & $\mathrm{CV}$ & 0.33335 & 0.24993 & 0.22211 & 0.27261 & 0.30759 & 0.35706 & 0.37495 & 0.35294 & 0.36852 & 0.30022 & 0.273 \\
\hline \multirow[t]{3}{*}{ wny10 } & $\mathrm{AIC}$ & 0.00026 & 0.00081 & 0.00126 & 0.00195 & 0.00292 & 0.00442 & 0.00649 & 0.00935 & 0.01516 & 0.02251 & 0.02505 \\
\hline & $\mathrm{T}$ & 4 & 4 & 5 & 8 & 9 & 10 & 11 & 12 & 14 & 15 & 17 \\
\hline & $\mathrm{CV}$ & 0.33331 & 0.5 & 0.4445 & 0.2728 & 0.3078 & 0.28585 & 0.31268 & 0.29435 & 0.25394 & 0.242 & 0.22765 \\
\hline
\end{tabular}


Annex 7 - SLI

\begin{tabular}{|c|c|c|c|c|c|c|c|c|c|c|}
\hline $\begin{array}{c}\text { Number } \\
\text { of terms }\end{array}$ & wny1 & wny2 & wny3 & wny4 & wny5 & wny6 & wny7 & wny8 & wny9 & wny10 \\
\hline 2 & 0.57739 & 0.56370 & 0.60388 & 0.53407 & 0.55663 & 0.57677 & 0.53052 & 0.66181 & 0.60756 & 0.53965 \\
\hline 3 & 0.63007 & 0.65353 & 0.56606 & 0.65563 & 0.58513 & 0.61979 & 0.57075 & 0.56877 & 0.62463 & 0.63872 \\
\hline 4 & 0.65239 & 0.62107 & 0.58437 & 0.60333 & 0.53042 & 0.63525 & 0.58240 & 0.52273 & 0.62519 & 0.62725 \\
\hline 5 & 0.69681 & 0.58683 & 0.63575 & 0.64729 & 0.55797 & 0.67894 & 0.61847 & 0.56436 & 0.64879 & 0.59561 \\
\hline 6 & 0.74204 & 0.67360 & 0.62187 & 0.72074 & 0.52283 & 0.69470 & 0.63889 & 0.60312 & 0.64913 & 0.63596 \\
\hline 7 & 0.75376 & 0.71422 & 0.58715 & 0.70417 & 0.54496 & 0.66741 & 0.59236 & 0.61684 & 0.62069 & 0.63601 \\
\hline 8 & 0.78308 & 0.72711 & 0.55416 & 0.76309 & 0.58593 & 0.71303 & 0.61190 & 0.64642 & 0.61302 & 0.66145 \\
\hline 9 & 0.77324 & 0.70719 & 0.54619 & 0.74955 & 0.55016 & 0.68633 & 0.61186 & 0.64393 & 0.64462 & 0.65155 \\
\hline 10 & 0.76948 & 0.61317 & 0.87935 & 0.75770 & 0.54151 & 0.60287 & 0.54566 & 0.64675 & 0.66326 & 0.62859 \\
\hline 11 & 0.69740 & 0.53632 & 0.79731 & 0.67682 & 0.50857 & 0.58222 & 0.51809 & 0.63305 & 0.61971 & 0.58230 \\
\hline 12 & 0.57332 & 0.69565 & 0.73375 & 0.54888 & 0.65033 & 0.66664 & 0.65657 & 0.53882 & 0.61196 & 0.60502 \\
\hline
\end{tabular}

